\title{
Functional Consequences of Sulfhydryl Modification of the $\gamma$-Aminobutyric Acid Transporter 1 at a Single Solvent-Exposed Cysteine Residue
}

\author{
Jaison J. Omoto • Matthew J. Maestas • Ali Rahnama-Vaghef • \\ Ye E. Choi - Gerardo Salto Jr. • Rachel V. Sanchez • \\ Cynthia M. Anderson · Sepehr Eskandari
}

Received: 10 April 2012/ Accepted: 16 July 2012/Published online: 24 August 2012

(C) The Author(s) 2012. This article is published with open access at Springerlink.com

\begin{abstract}
The aims of this study were to optimize the experimental conditions for labeling extracellularly oriented, solvent-exposed cysteine residues of $\gamma$-aminobutyric acid transporter 1 (GAT1) with the membrane-impermeant sulfhydryl reagent [2-(trimethylammonium)ethyl]methanethiosulfonate (MTSET) and to characterize the functional and pharmacological consequences of labeling on transporter steady-state and presteady-state kinetic properties. We expressed human GAT1 in Xenopus laevis oocytes and used radiotracer and electrophysiological methods to assay transporter function before and after sulfhydryl modification with MTSET. In the presence of $\mathrm{NaCl}$, transporter exposure to MTSET (1-2.5 $\mathrm{mM}$ for 5-20 min) led to partial inhibition of GAT1-mediated transport, and this loss of function was completely reversed by the reducing reagent dithiothreitol. MTSET treatment had no functional effect on the mutant GAT1 C74A, whereas the membrane-permeant reagents $N$-ethylmaleimide and tetramethylrhodamine-6maleimide inhibited GABA transport mediated by GAT1 C74A. Ion replacement experiments indicated that MTSET labeling of GAT1 could be driven to completion when valproate replaced chloride in the labeling buffer, suggesting that valproate induces a GAT1 conformation that significantly increases C74 accessibility to the extracellular fluid. Following partial inhibition by MTSET, there was a
\end{abstract}

J. J. Omoto - M. J. Maestas · A. Rahnama-Vaghef .

Y. E. Choi · G. Salto Jr. · R. V. Sanchez •

C. M. Anderson - S. Eskandari $(\square)$

Biological Sciences Department, California State Polytechnic

University, Pomona, 3801 West Temple Avenue,

Pomona, CA 91768-4032, USA

e-mail: seskandari@csupomona.edu proportional reduction in both the presteady-state and steady-state macroscopic signals, and the functional and pharmacological properties of the remaining signals were indistinguishable from those of unlabeled GAT1. Therefore, covalent modification of GAT1 at C74 results in completely nonfunctional as well as electrically silent transporters.

Keywords Neurotransmitter:sodium symporter - SLC6 . GABA transporter - SLC6A1 - Sulfhydryl modification . Cysteine 74

\section{Introduction}

In the nervous system, removal of the inhibitory neurotransmitter $\gamma$-aminobutyric acid (GABA) from the extracellular space of neurons and glia is accomplished by electrogenic $\mathrm{Na}^{+}$- and $\mathrm{Cl}^{-}$-coupled GABA transporters (GATs) (Borden 1996; Nelson 1998; Dalby 2003; Richerson and $\mathrm{Wu} 2003$; Conti et al. 2004). Four GAT isoforms exist in mammalian tissues and belong to the large neurotransmitter/ $\mathrm{Na}^{+}$symporter family (NSS; 2.A.22 according to the transporter classification system; SLC6 according to the Human Genome Organization classification) (Nelson 1998; Busch and Saier 2002; Chen et al. 2004; Saier et al. 2006). Two sets of nomenclature systems are used to refer to the GATs: rat/human GAT-1, BGT-1, GAT-2 and GAT-3 correspond to mouse GAT1, GAT2, GAT3 and GAT4, respectively. GAT1 was the first family member to be cloned (Guastella et al. 1990; Nelson et al. 1990) and paved the way for the cloning and characterization of the related serotonin, dopamine, norepinephrine and glycine transporters (Blakely et al. 1991; Hoffman et al. 1991; Kilty et al. 
1991; Pacholczyk et al. 1991; Shimada et al. 1991; Usdin et al. 1991; Guastella et al. 1992; Liu et al. 1992). GAT1 is the most abundant isoform within the nervous system and is expressed in both neurons and glia (Conti et al. 2004; Madsen et al. 2010). Tiagabine, a specific inhibitor of GAT1, is used clinically as an anticonvulsant drug and highlights the importance of GAT1 in maintaining GABA homeostasis in the brain extracellular fluid (Dalby 2003; Schousboe et al. 2011).

Chemical modification of endogenous or engineered cysteine residues has served as an important tool for structure-function studies of membrane proteins (Frillingos et al. 1998; Rudnick 2006; Guan and Kaback 2007; see also Anderson et al. 2010); and, in particular, when coupled with high-resolution information from crystal structures, sulfhydryl modification has served as a powerful tool to address specific questions regarding the functional role of targeted residues. Ideally, individual cysteine residues are engineered in the primary protein sequence against a cysteineless background. Covalent modification of the introduced cysteine with thiol-specific probes, many of which differ in chemical properties, would then provide insight regarding the role that the residue in question plays in protein function. In practice, however, cysteine-less membrane proteins are difficult to study as they may not be properly trafficked to the plasma membrane or may be nonfunctional. Therefore, many investigators have relied on labeling endogenous cysteines in order to glean insight about protein function. This happens to be the case with GAT1. The extracellularly exposed, endogenous cysteine residue of GAT1, cysteine 74 (C74), has been used to gain insight into the nature and functional consequences of sulfhydryl modification at this residue (Bennett and Kanner 1997; Yu et al. 1998; Golovanevsky and Kanner 1999; Li et al. 2000; Kanner 2003; Zomot and Kanner 2003; Zhou et al. 2004, 2006; Zhou and Kanner 2005; Zomot et al. 2005; Mari et al. 2006; Rosenberg and Kanner 2008; Ben-Yona and Kanner 2009; Meinild et al. 2009). While it has been shown that sulfhydryl modification at $\mathrm{C} 74$ renders the transporter nonfunctional, the mechanism of this effect is not known. In previous studies, rather harsh labeling conditions were required to achieve any significant degree of GAT1 C74 labeling, which made it difficult to carry out a thorough biophysical characterization of the labeled transporter.

With the long-term goal of utilizing endogenous, extracellularly oriented, solvent-exposed cysteine residues of GAT1 for specific and targeted transporter labeling in the Xenopus laevis oocyte plasma membrane, we set out to fully characterize the functional consequences of sulfhydryl modification of GAT1 with the membrane-impermeant sulfhydryl reagent [2-(trimethylammonium)ethyl]methanethiosulfonate (MTSET). Our data suggest that C74 is very likely the only functionally sensitive residue labeled by MTSET and that such labeling renders the transporter nonfunctional as well as electrically silent with respect to all known electrophysiological assays of transporter function (steady-state and presteady-state measurements). Labeling in the presence of valproate, an anion that specifically interacts with GAT1 and increases the rate of $\mathrm{Na}^{+} / \mathrm{Cl}^{-} / \mathrm{GABA}$ cotransport (Whitlow et al. 2003), significantly increases the accessibility of C74 to the extracellular fluid and, hence, allows for rapid and complete labeling of all transporter copies at the cell surface. Our findings have established the optimal conditions for labeling GAT1 in the plasma membrane and set the stage for future structure-function studies.

\section{Experimental Procedures}

Expression of Wild-type (WT) and Mutant GAT1 in $X$. laevis Oocytes

Stage V-VI X. laevis oocytes were injected with $50 \mathrm{ng}$ of complementary RNA (cRNA) for human GAT1 (SLC6A1) (Nelson et al. 1990; Chen et al. 2004) or the mutant GAT1 C74A. The GAT1 C74A mutant was generated by polymerase chain reaction site-directed mutagenesis using the QuikChange Lightning Site-Directed Mutagenesis Kit (Agilent Technologies, La Jolla, CA). The sense ( $5^{\prime}$ GG TTC CCC TAT CTC GCC GGG AAA AAT GGT GGG $3^{\prime}$ ) and antisense ( $3^{\prime}$ CC AAG GGG ATA GAG CGG CCC TTT TTA CCA CCC $5^{\prime}$ ) mutagenic primers were synthesized by Retrogen (San Diego, CA); underlined bases denote the mutated codon. Following site-directed mutagenesis, the entire coding region of the plasmid containing GAT1 C74A was sequenced (Retrogen) to confirm the proper introduction of the mutation. cRNA for (WT) GAT1, or GAT1 C74A, was synthesized in vitro using T7 RNA polymerase (mMessage mMachine T7 Kit; Applied Biosystems/Ambion, Austin, TX). After cRNA injection, oocytes were maintained in Barth's medium (in mM: $88 \mathrm{NaCl}, 1 \mathrm{KCl}, 0.33 \mathrm{Ca}\left(\mathrm{NO}_{3}\right)_{2}$, $0.41 \mathrm{CaCl}_{2}, 0.82 \mathrm{MgSO}_{4}, 2.4 \mathrm{NaHCO}_{3}$ and 10 HEPES [pH 7.4] as well as $50 \mu \mathrm{g} / \mathrm{ml}$ gentamicin, $100 \mu \mathrm{g} / \mathrm{ml}$ streptomycin and $100 \mathrm{U} / \mathrm{ml}$ penicillin) at $18{ }^{\circ} \mathrm{C}$ for up to 14 days until used in experiments. Unless otherwise indicated, all experiments were performed at $21 \pm 2{ }^{\circ} \mathrm{C}$.

\section{Experimental Solutions and Reagents}

Unless otherwise indicated, experiments were performed in $\mathrm{NaCl}$ buffer containing (in $\mathrm{mM}$ ) $100 \mathrm{NaCl}, 2 \mathrm{KCl}, 1 \mathrm{CaCl}_{2}, 1$ $\mathrm{MgCl}_{2}$ and 10 HEPES ( $\mathrm{pH}$ 7.4). In experiments which required $\mathrm{Na}^{+}$-free conditions, $\mathrm{NaCl}$ was isosmotically replaced, depending on the experimental protocol, with choline- $\mathrm{Cl}, \mathrm{LiCl}, \mathrm{KCl}, \mathrm{CsCl}$ or tetraethylammonium-chloride. In experiments which required $\mathrm{Cl}^{-}$-free conditions, $\mathrm{NaCl}$ was isosmotically replaced with $\mathrm{Na}-[2-(\mathrm{N}$-morpholino) 
ethanesulfonic acid], Na-gluconate or Na-(2-propylpentanoic acid) (Na-valproate). In chloride-free buffers, $\mathrm{KCl}, \mathrm{CaCl}_{2}$ and $\mathrm{MgCl}_{2}$ were replaced with their corresponding gluconate salts. The buffers used for solutions at $\mathrm{pH} 5.0$ and 9.0 were MES and $N$-tris(hydroxymethyl)methyl-3-aminopropanesulfonic acid, respectively. GABA, 1-(4,4-diphenyl-3-butenyl)3-piperidinecarboxylic acid (SKF-89976A), 1-[2-[[(diphenylmethylene)imino]oxy]ethyl]-1,2,5,6-tetrahydro-3-pyridi necarboxylic acid (NO-711), MTSET, 2-[(methylsulfonyl) thio]ethanesulfonic acid (MTSES, sodium salt), $N$-ethylmaleimide (NEM), tetramethylrhodamine-6-maleimide (TMR6M) and/or dithiothreitol (DTT) was added to the experimental solution as indicated. Stock solutions of sulfhydryl reagents (MTSET, MTSES, NEM and TMR6M) were stored in nanopure water (MTSET, MTSES), absolute ethanol (NEM) or dimethyl sulfoxide (TMR6M) at $-20{ }^{\circ} \mathrm{C}$ and diluted in the experimental solution immediately before use. DTT was prepared from the solid material immediately before use. MTSET and MTSES were purchased from Toronto Research Chemicals (Toronto, ON, Canada) or Anatrace (Maumee, OH). TMR6M was purchased from Invitrogen (Carlsbad, CA). $\left[{ }^{3} \mathrm{H}\right]-\mathrm{GABA}$ was obtained from GE Healthcare (Piscataway, NJ). All other reagents were purchased from Fisher Scientific (Pittsburgh, PA) or Sigma (St. Louis, MO).

\section{Electrophysiological Measurements and Data Analysis}

The two-microelectrode voltage-clamp technique was used for the recording of whole-cell transporter-mediated currents. Oocytes were voltage-clamped at the indicated membrane potential $\left(V_{\mathrm{m}}\right)$ using the Warner oocyte clamp (OC-725C; Warner Instrument; Hamden, CT). In the experimental recording chamber, oocytes were initially stabilized in $\mathrm{NaCl}$ buffer, and the composition of the bath was changed as indicated. In all experiments, reference electrodes were connected to the experimental oocyte chamber via agar bridges ( $3 \%$ agar in $3 \mathrm{M} \mathrm{KCl}$ ). For continuous holding current measurements, currents were low pass-filtered at $1 \mathrm{~Hz}$ (LPF 8, Warner Instrument) and sampled at $10 \mathrm{~Hz}$ (pCLAMP 8.1; Axon Instruments, Union City, CA). The GABA-evoked current was obtained as the difference in steady-state current in the absence and presence of GABA and/or inhibitor. As the GAT1-mediated, GABA-evoked current is $\mathrm{Na}^{+}$- and $\mathrm{Cl}^{-}$-coupled (Loo et al. 2000), it is referred to as $I_{\mathrm{NaCl}}^{\mathrm{GABA}}$ (Gonzales et al. 2007).

The effects of substrate concentration ( $\left.[\mathrm{GABA}]_{\mathrm{o}}, \mathrm{Na}^{+}\right]_{\mathrm{o}}$ and $\left[\mathrm{Cl}^{-}\right]_{\mathrm{o}}$ ) on the steady-state kinetics were determined by nonlinear curve fitting of the induced currents $(I)$ with Eq. 1 :

$$
I=\frac{I_{\max }^{S} \cdot[S]^{n}}{\left(K_{0.5}^{S}\right)^{n}+[S]^{n}}
$$

where $S$ is the substrate $\left(\mathrm{GABA}, \mathrm{Na}^{+}\right.$or $\left.\mathrm{Cl}^{-}\right), I_{\max }^{S}$ is the maximal substrate-induced current, $K_{0.5}^{S}$ is the substrate concentration at half $I_{\max }^{S}$ (half-maximal concentration) and $n$ is the Hill coefficient. For kinetic characterization of $\mathrm{Cl}^{-}$ activation of the inward currents, an additional linear term was added to Eq. 1 in order to account for the nonzero baseline at zero $\mathrm{Cl}^{-}$concentration (see Fig. $6 \mathrm{~g}-\mathrm{i}$ ).

To examine the carrier-mediated presteady-state current transients, the pulse protocol consisted of voltage jumps $(400 \mathrm{~ms})$ from the holding voltage $(-50 \mathrm{mV})$ to test voltages ranging from +80 to $-130 \mathrm{mV}$ in $15-\mathrm{mV}$ steps. Unless otherwise indicated, voltage pulses were separated by an interval of at least $3 \mathrm{~s}$ in order to allow for complete relaxation of the OFF transients (see Sacher et al. 2002; Karakossian et al. 2005). Currents were low pass-filtered at $1 \mathrm{kHz}$ and sampled at $12.5 \mathrm{kHz}$ without averaging. To obtain the transporter presteady-state currents, at each $V_{\mathrm{m}}$, the total current for the ON transients, $I(t)$, was fitted with Eq. 2:

$I(t)=I_{1} e^{-t / \tau_{1}}+I_{2} e^{-t / \tau_{2}}+I_{\mathrm{SS}}$

where $t$ is time, $I_{1} e^{-t / \tau_{1}}$ is the oocyte capacitive transient current with initial value $I_{1}$ and time constant $\tau_{1}, I_{2} e^{-t / \tau_{2}}$ is the transporter transient current with initial value $I_{2}$ and time constant $\tau_{2}$ and $I_{\mathrm{ss}}$ is the steady-state current (Loo et al. 1993; Hazama et al. 1997). At each $V_{\mathrm{m}}$, the total transporter-mediated charge $(Q)$ was obtained by integration of the transporter transient currents. The charge-voltage $(Q-V)$ relations obtained were then fitted with a single Boltzmann function (Eq. 3):

$$
\frac{Q-Q_{\mathrm{hyp}}}{Q_{\mathrm{NaCl}}}=\frac{1}{1+e^{\left[\frac{-\delta \delta\left(V_{\mathrm{m}}-V_{0.5}\right)}{R T}\right]}}
$$

where $Q_{\mathrm{NaCl}}=Q_{\mathrm{dep}}-Q_{\text {hyp }}\left(Q_{\mathrm{dep}}\right.$ and $Q_{\text {hyp }}$ are $Q$ at depolarizing and hyperpolarizing limits, respectively) and represents the maximum charge moved (i.e., $Q_{\max }$ ), $z$ is the apparent valence of movable charge, $\delta$ is the fraction of the membrane electric field traversed by the charge, $V_{0.5}$ is the $V_{\mathrm{m}}$ for $50 \%$ charge movement, $F$ is Faraday's constant, $R$ is the gas constant and $T$ is the absolute temperature.

The inhibition experiments involved GAT1-specific competitive inhibitors of GABA transport (SKF-89976A and NO711). Data for the inhibition experiments were fitted with Eq. 4 (Krause and Schwarz 2005; Matthews et al. 2009):

$$
\frac{I}{I_{\max }}=\frac{[\mathrm{GABA}]}{K_{0.5}^{\mathrm{GABA}} \times\left(1+\frac{[B]}{K_{i}^{B}}\right)+[\mathrm{GABA}]}
$$

where $I_{\max }$ is the maximum current evoked by a saturating concentration of GABA in the absence of the blocker $(B$, here SKF-89976A or NO-711), $I$ is the evoked current in the presence of the indicated concentrations of GABA and 
blocker $(B), K_{0.5}^{\mathrm{GABA}}$ is the GABA concentration at which $I$ is half of $I_{\max }(25 \mu \mathrm{M}$ at $-50 \mathrm{mV})$ (Gonzales et al. 2007) and $K_{i}^{B}$ is the blocker concentration at which $I$ is $50 \%$ of $I_{\text {max }}$ (apparent half-inhibition constant).

To determine the effect of sulfhydryl modification on the ratio of GAT1-mediated charge flux to GABA flux across the plasma membrane, uptake experiments were performed under voltage clamp in individual control oocytes and oocytes expressing WT GAT1 (Eskandari et al. 1997; Forster et al. 1999; Loo et al. 2000; Sacher et al. 2002; Whitlow et al. 2003; Karakossian et al. 2005; Gonzales et al. 2007; Matthews et al. 2009). The membrane potential was held at the indicated value $(-50 \mathrm{mV})$, and the holding current was continuously monitored. Oocytes were initially incubated in $\mathrm{NaCl}$ buffer until a baseline was established. GABA $(500 \mu \mathrm{M})$ and $\left[{ }^{3} \mathrm{H}\right]-\mathrm{GABA}$ $(20 \mathrm{nM})$ were added to the perfusion solution for 5-10 min. At the end of the incubation period, GABA and the isotope were removed from the perfusion solution until the holding current returned to baseline. Oocytes were removed from the experimental chamber, washed in ice-cold choline-Cl buffer and solubilized in $10 \%$ sodium dodecyl sulfate (SDS). Oocyte $\left[{ }^{3} \mathrm{H}\right]-\mathrm{GABA}$ content was determined in a liquid scintillation counter (LS 6500; Beckman, Fullerton, CA). Net inward charge was obtained from the time integral of the GABAevoked inward current and correlated with GABA influx in the same cell. GABA uptake under voltage clamp was also performed in oocytes expressing WT GAT1 after a 5-min exposure to $1 \mathrm{mM}$ MTSET in $\mathrm{NaCl}$ buffer. This treatment reduces the GAT1-mediated, GABA-evoked current by approximately $50 \%$ (see Figs. 1, 2, 3, 4, 7). In all experiments, the GAT1-mediated GABA uptake was obtained by subtracting endogenous GABA uptake in control cells from the same batch that were subjected to the same experimental condition as GAT1-expressing cells. Depending on the level of GAT1 expression in the plasma membrane as well as the duration of GABA exposure (5-10 $\mathrm{min})$, the magnitude of endogenous GABA uptake was $0.5-5 \%$ of the total GABA uptake (endogenous plus GAT1-mediated uptake).

Where sample sizes are indicated $(n)$, they refer to the number of oocytes in which the experiments were repeated. Reported errors represent the standard error of the mean obtained from data from several oocytes.

\section{Results}

Labeling with the Membrane-Impermeant Sulfhydryl Reagent MTSET Leads to Functional Modification of WT GAT1 but not the Mutant GAT1 C74A

Figure 1 shows the basic experimental approach used to assess the effect of sulfhydryl modification on the
GABA-evoked current mediated by GAT1 $\left(I_{\mathrm{NaCl}}^{\mathrm{GABA}}\right) . I_{\mathrm{NaCl}}^{\mathrm{GABA}}$ is proportional to the number of functional transporters in the plasma membrane and is directly related to $\mathrm{Na}^{+} / \mathrm{Cl}^{-}$/ GABA cotransport across the plasma membrane (Loo et al. 2000; Gonzales et al. 2007; Matthews et al. 2009). It is, therefore, a good assay of GAT function. In a typical experiment, $I_{\mathrm{NaCl}}^{\mathrm{GABA}}$ was measured in $\mathrm{NaCl}$ buffer (plus $500 \mu \mathrm{M}$ GABA) before and after exposure to MTSET. In the experiments of Fig. 1, MTSET labeling was carried out in $\mathrm{NaCl}$ buffer at $1 \mathrm{mM}$ for $5 \mathrm{~min}$ (at $21 \pm 2{ }^{\circ} \mathrm{C}, V_{\mathrm{m}}=$ $-50 \mathrm{mV}, \mathrm{pH}$ 7.4). The evoked current obtained after MTSET exposure was normalized to that before MTSET and was $52 \pm 1 \%$ of the original value $(n=4)$ (Fig. 1a, d). Treatment with the membrane-impermeant MTSES (at $1 \mathrm{mM}$ for $5 \mathrm{~min}$ at $21 \pm 2{ }^{\circ} \mathrm{C}, V_{\mathrm{m}}=-50 \mathrm{mV}, \mathrm{pH} 7.4$ ) reduced $I_{\mathrm{NaCl}}^{\mathrm{GABA}}$ by only $22 \pm 2 \%$ ( $n=3$, data not shown). Therefore, we focused on the effect of MTSET for the remaining experiments of this study. In all subsequent experiments, where normalized current values are reported, they always refer to measurements obtained in $\mathrm{NaCl}$ buffer (500 $\mu \mathrm{M}$ GABA at $\left.21 \pm 2{ }^{\circ} \mathrm{C}, V_{\mathrm{m}}=-50 \mathrm{mV}, \mathrm{pH} 7.4\right)$. However, the labeling conditions were altered depending on the experimental objective. Unless otherwise stated, the labeling conditions consisted of $1 \mathrm{mM}$ MTSET for $5 \mathrm{~min}$ in $\mathrm{NaCl}$ buffer at $21 \pm 2{ }^{\circ} \mathrm{C}, V_{\mathrm{m}}=-50 \mathrm{mV}, \mathrm{pH} 7.4$.

Similar to WT GAT1, GAT1 C74A mediates $\mathrm{Na}^{+}$dependent and $\mathrm{Cl}^{-}$-facilitated GABA transport (see Fig. 6). Exposure of GAT1 C74A to MTSET (1 mM for $5 \mathrm{~min}$ ) had no effect on the magnitude of the GABAevoked current (Fig. 1b, d). This result suggests that C74 is very likely the only functionally significant cysteine residue that is exposed to the extracellular fluid (and hence accessible to the membrane-impermeant MTSET).

The reduction in WT GAT $1 I_{\mathrm{NaCl}}^{\mathrm{GABA}}$ caused by MTSET sulfhydryl modification was completely reversible with DTT. Following DTT treatment (12 mM for $10 \mathrm{~min})$, $I_{\mathrm{NaCl}}^{\mathrm{GABA}}$ returned to $98 \pm 3 \%$ of its original level before MTSET labeling $(n=5)$ (Fig. 1c, d). Treatment of WT GAT1 with DTT, either before or during exposure to GABA, was without any effect on the GABA-evoked current. In the copresence of $500 \mu \mathrm{M}$ GABA and $10 \mathrm{mM}$ DTT, $I_{\mathrm{NaCl}}^{\mathrm{GABA}}$ was $98 \pm 2 \%$ of that measured in the same cell in the absence of DTT ( $n=3)$ (not shown).

The above results suggest that any functional consequence of sulfhydryl modification of WT GAT1 by MTSET very likely occurred at position C74. NEM, a membrane-permeant thiol modification reagent, led to a significant reduction in $I_{\mathrm{NaCl}}^{\mathrm{GABA}}$ mediated by both WT GAT1 $(21 \pm 5 \%, n=4)$ and GAT1 C74A $(51 \pm 6 \%, n=5)$ (Fig. 1d). These results further suggest that C74 is very likely the only functionally sensitive cysteine residue exposed to the extracellular fluid. TMR6M, a fluorescent 
A

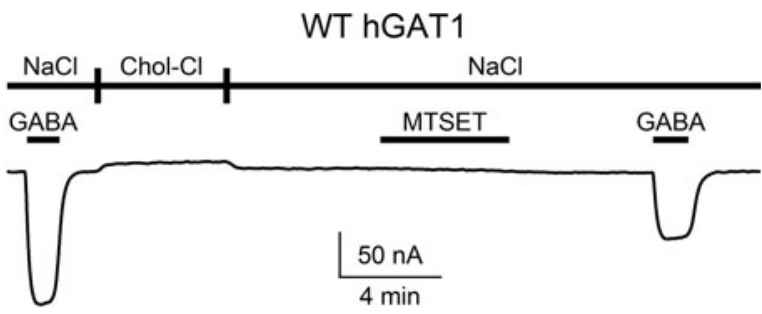

B

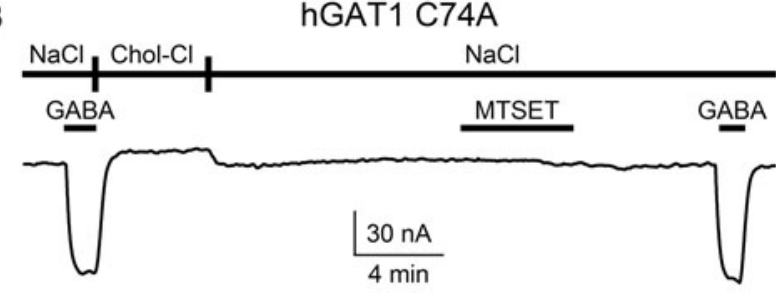

C
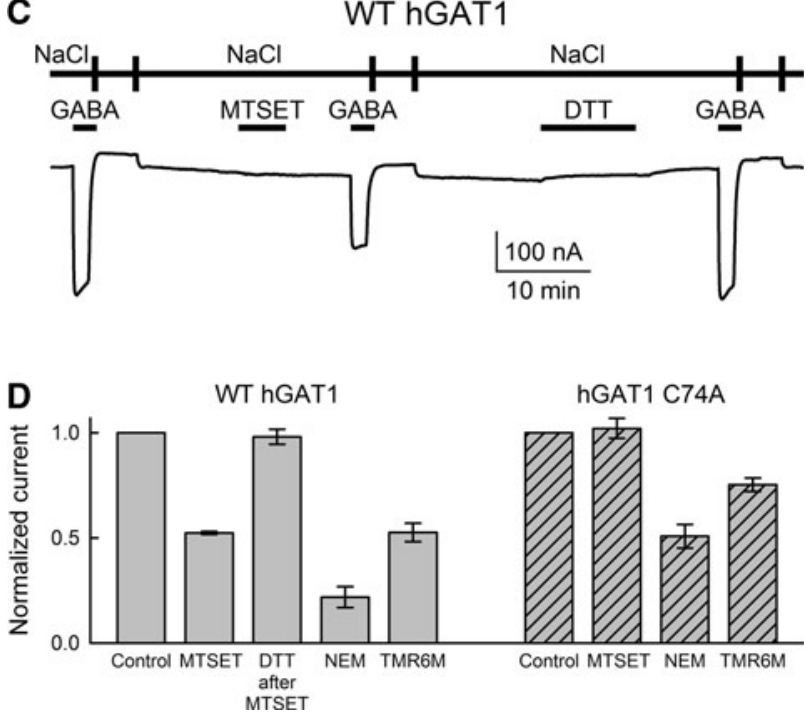

Fig. 1 WT GAT1, but not GAT1 C74A, is sensitive to membraneimpermeant sulfhydryl reagents. a A representative GABA-evoked $(500 \mu \mathrm{M})$ current trace is shown for WT GAT1 before and after labeling with the membrane-impermeant sulfhydryl reagent MTSET. Labeling of GAT1 with MTSET led to $\sim 50 \%$ reduction in the GABA-evoked current. The membrane potential $\left(V_{\mathrm{m}}\right)$ was $-50 \mathrm{mV}$ throughout the experiment. Labeling was carried out at $1 \mathrm{mM}$ MTSET for $5 \mathrm{~min}$ in $\mathrm{NaCl}$ buffer bathing the oocyte (at $21 \pm 2{ }^{\circ} \mathrm{C}, \mathrm{pH} 7.4$ ). b Similar to WT GAT1, GAT1 C74A mediates $\mathrm{Na}^{+}$-dependent and $\mathrm{Cl}^{-}$-facilitated GABA transport (see Fig. 6). Exposure of GAT1 C74A to MTSET ( $1 \mathrm{mM}$ for $5 \mathrm{~min}$ ) had no effect on the magnitude of the GABA-evoked $(500 \mu \mathrm{M})$ current. c Sulfhydryl modification of WT GAT1 with MTSET was completely reversed with DTT. Labeling with MTSET was carried out as in (a), and DTT was applied at $12 \mathrm{mM}$ for $10 \mathrm{~min}$ in $\mathrm{NaCl}$ buffer. d Summary of data collected from four or more oocytes expressing WT GAT1 or GAT1 C74A. For each experimental condition, the GABA-evoked current obtained after labeling with MTSET, NEM or TMR6M (all at $1 \mathrm{mM}$ for $5 \mathrm{~min}$ at $-50 \mathrm{mV}$ ) was normalized to that prior to sulfhydryl modification in the same cell. Reported values represent the mean \pm SE from four or more oocytes. Note that GAT1 C74A is insensitive to the membrane-impermeant MTSET but sensitive to the membrane-permeant NEM. GAT1 C74A was also sensitive to TMR6M probe commonly used for labeling membrane proteins at solvent-exposed cysteine residues, reduced $I_{\mathrm{NaCl}}^{\mathrm{GABA}}$ mediated by WT GAT1 to $53 \pm 4 \%(n=3)$ and that mediated by GAT1 C74A to $75 \pm 3 \%(n=6)$ of control levels (Fig. 1d).

As the long-term objective of this project is to utilize extracellularly exposed cysteine residues to label and quantify the number of transporter copies in the plasma membrane, we carried out a complete characterization of labeling WT GAT1 with MTSET with the goal of identifying experimental conditions that drive the labeling reaction to completion (i.e., $100 \%$ labeling of transporter copies in the plasma membrane). Understanding these conditions would then allow us to pursue future labeling and quantification studies.

The Inhibitory Effect of MTSET is Dependent on the Composition of the Labeling Buffer

GABA transport by the GATs is $\mathrm{Na}^{+}$- and $\mathrm{Cl}^{-}$-coupled, and indeed, $\mathrm{Na}^{+}$and $\mathrm{Cl}^{-}$interaction with the transporter leads to conformational changes (Golovanevsky and Kanner 1999; Lu and Hilgemann 1999b; Li et al. 2000; Zomot and Kanner 2003; Meinild et al. 2009). Therefore, we explored the possibility that the ionic composition of the buffer in which the MTSET exposure takes place can potentially enhance the solvent accessibility of $\mathrm{C} 74$, thus increasing the degree of labeling. To accomplish this, we investigated the degree of MTSET labeling when $\mathrm{Na}^{+}$ and/or $\mathrm{Cl}^{-}$was isosmotically replaced with various cations/anions in the labeling buffer, keeping all other labeling conditions constant $(1 \mathrm{mM}$ MTSET for $5 \mathrm{~min}$ at $21 \pm$ $\left.2{ }^{\circ} \mathrm{C}, V_{\mathrm{m}}=-50 \mathrm{mV}, \mathrm{pH} 7.4\right)$.

Labeling with MTSET in the standard $\mathrm{NaCl}$ conditions reduced $I_{\mathrm{NaCl}}^{\mathrm{GABA}}$ to $52 \pm 1 \%$ of control levels (Figs. 1, 2). When $\mathrm{Na}^{+}$in the labeling buffer was replaced with other cations such as choline, TEA, $\mathrm{Cs}^{+}, \mathrm{K}^{+}$or $\mathrm{Li}^{+}$, there was only a marginal enhancement of the inhibitory effect of MTSET (Fig. 2). The largest effect of $\mathrm{Na}^{+}$replacement was seen with $\mathrm{Li}^{+}$(Fig. 2). Similarly, replacing $\mathrm{Cl}^{-}$in the labeling buffer with anions such as MES or gluconate only modestly enhanced the inhibitory effect of MTSET. Neither replacement of both $\mathrm{Na}^{+}$and $\mathrm{Cl}^{-}$in the labeling buffer (with TEA and MES, respectively) nor increasing the $\mathrm{NaCl}$ concentration to $150 \mathrm{mM}$ led to any significant increase in the degree of MTSET labeling (Fig. 2). Notably, labeling with MTSET when $\mathrm{Cl}^{-}$was replaced with valproate resulted in significantly enhanced efficacy of the MTSETdependent reduction in $I_{\mathrm{NaCl}}^{\mathrm{GABA}}(13 \pm 2 \%$ of control, $n=4)$. On the other hand, the presence of GABA during MTSET treatment protected against transporter labeling (Fig. 2). Addition of 0.5 and $5 \mathrm{mM} \mathrm{GABA}$ to the labeling 


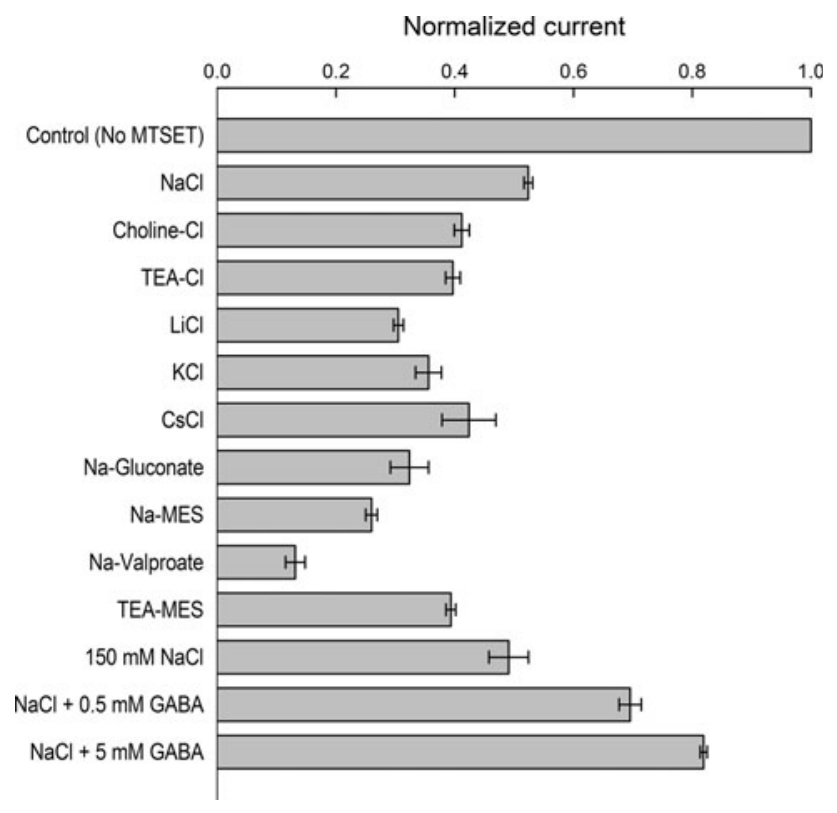

Fig. 2 Effect of buffer composition on MTSET labeling of WT GAT1. WT GAT1 was labeled with MTSET in the indicated extracellular bathing solution, in which $\mathrm{Na}^{+}$and/or $\mathrm{Cl}^{-}$of the $\mathrm{NaCl}$ buffer had been isosmotically replaced by another cation or anion, respectively. The experimental protocol was similar to that shown in Fig. 1 (5-min exposure to $1 \mathrm{mM}$ MTSET at $-50 \mathrm{mV}, 21 \pm 2{ }^{\circ} \mathrm{C}, \mathrm{pH}$ 7.4) with the exception that sulfhydryl modification was carried out in the indicated buffer. The GABA-evoked $(500 \mu \mathrm{M}$ in $\mathrm{NaCl}$ buffer) current after MTSET modification was normalized to that obtained in the same cell before exposure to MTSET. Reported values represent the mean $\pm \mathrm{SE}$ from three or more oocytes

buffer reduced $I_{\mathrm{NaCl}}^{\mathrm{GABA}}$ to only $70 \pm 3 \%(n=3)$ and $82 \pm$ $2 \%(n=3)$ of control levels prior to MTSET labeling (Fig. 2).
Changes in Membrane Potential, $\mathrm{pH}$ and Temperature Do Not Alter the Effect of MTSET

GAT activity is also known to be altered by changes in membrane potential (Mager et al. 1993, 1996; Lu and Hilgemann 1999a, b; Gonzales et al. 2007), pH (Grossman and Nelson 2002, 2003) and temperature (Lu and Hilgemann 1999a; Binda et al. 2002; Gonzales et al. 2007; Matthews et al. 2009). Therefore, we examined the influence of these factors on the degree of MTSET labeling of GAT1. In the experiments of Fig. 3, membrane potential $\left(V_{\mathrm{m}}\right), \mathrm{pH}$ and temperature were independently perturbed during the MTSET labeling period, while all other parameters were held constant according to our standard labeling conditions: $1 \mathrm{mM}$ MTSET for $5 \mathrm{~min}$ at $21 \pm 2{ }^{\circ} \mathrm{C}, V_{\mathrm{m}}=-50 \mathrm{mV}$ and $\mathrm{pH}$ 7.4. Interestingly, changes in the membrane potential or $\mathrm{pH}$ of the labeling buffer or in temperature had little to no effect on the efficacy of MTSET labeling (Fig. 3). The apparent reduction in MTSET labeling at lower $\mathrm{pH}$ values (Fig. 3b) is unlikely to be a direct conformational effect on the transporter (see "Discussion" Section).

\section{MTSET Labeling Conditions for Complete Elimination of GAT1-Mediated GABA Transport}

In further pursuit of the optimal experimental conditions under which MTSET labeling of WT GAT1 would approach completion, we examined the effect of MTSET concentration (Fig. 4a) and labeling duration (Fig. 4c) on GAT1-mediated, GABA-evoked current. The concentration dependence of MTSET labeling in $\mathrm{NaCl}$ buffer is shown in Fig. 4a. Keeping all other labeling conditions constant, increasing the concentration of MTSET from 1 to
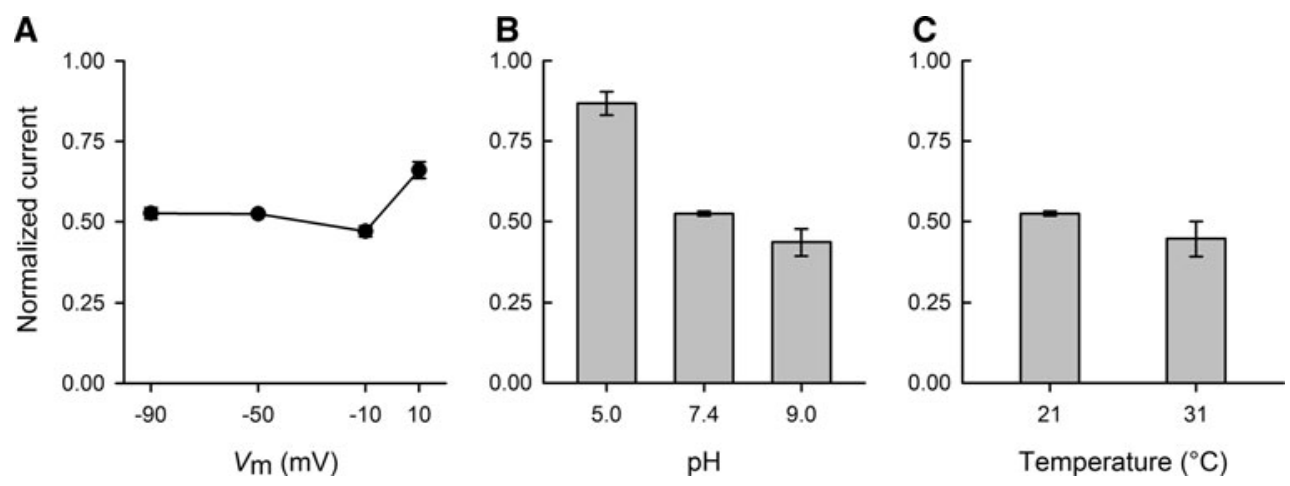

Fig. 3 Effect of membrane potential, $\mathrm{pH}$ and temperature on MTSET labeling of WT GAT1. The GABA-evoked $(500 \mu \mathrm{M}$ at $-50 \mathrm{mV})$ current mediated by WT GAT1 was measured before and after MTSET labeling (1 $\mathrm{mM}$ for $5 \mathrm{~min}$ ) at different membrane potential values (a), extracellular $\mathrm{pH}$ values (b) and experimental temperatures (c). In all experiments, labeling was carried out in $\mathrm{NaCl}$ buffer. Labeling was performed at the indicated membrane potential values for the experiments of $\mathbf{a}$ and at $-50 \mathrm{mV}$ for the experiments of (b) and (c). Labeling was performed at $\mathrm{pH} 7.4$ for the experiments of (a) and (c) and at the indicated values for the experiments of (b). Labeling was performed at $21^{\circ} \mathrm{C}$ for the experiments of (a) and (b) and at the indicated values for the experiments of (c). The GABAevoked current after MTSET modification was normalized to that obtained in the same cell before exposure to MTSET. Reported values represent the mean $\pm \mathrm{SE}$ from three or more oocytes 

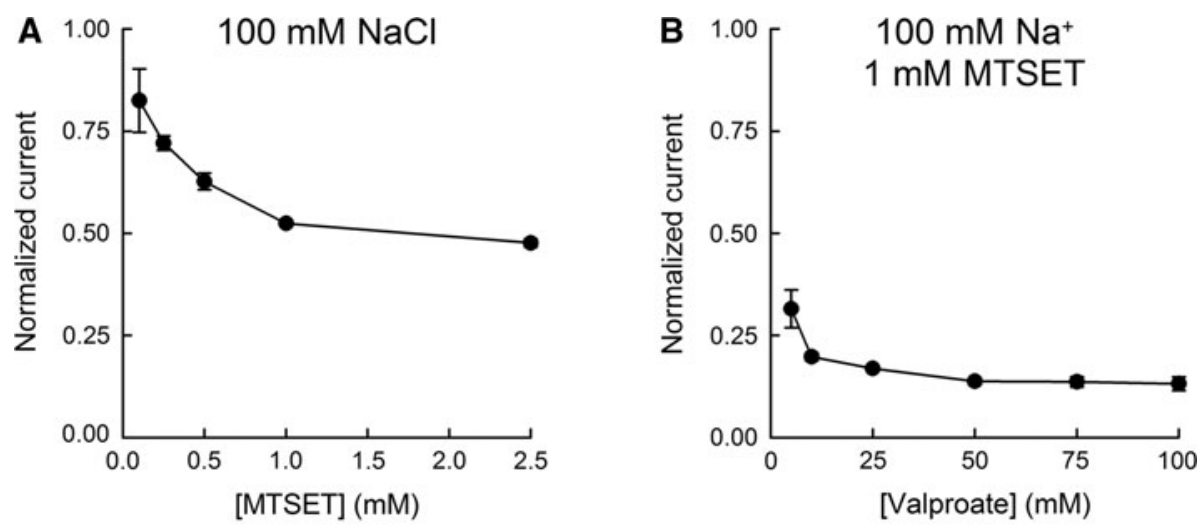

C

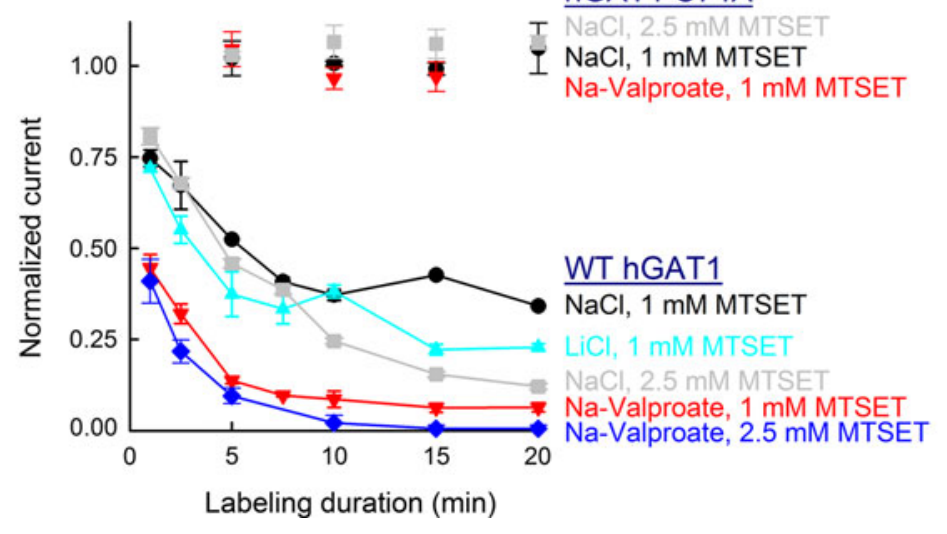

Fig. 4 Effect of MTSET concentration and labeling duration on sulfhydryl modification of WT GAT1. a Sulfhydryl modification of WT GAT1 was carried out for $5 \mathrm{~min}$ in $\mathrm{NaCl}$ buffer in the presence of the indicated concentration of MTSET. b Sulfhydryl modification of WT GAT1 was carried out at $1 \mathrm{mM}$ MTSET for $5 \mathrm{~min}$ in the presence of the indicated concentration of valproate. $\left[\mathrm{Na}^{+}\right]=100 \mathrm{mM}$. $\mathbf{c}$ Duration of labeling with 1 or $2.5 \mathrm{mM}$ MTSET was varied (up to $20 \mathrm{~min}$ ) in $\mathrm{NaCl}$, $\mathrm{LiCl}$ or Na-valproate buffer for WT GAT1 or GAT1 C74A. Note that

$2.5 \mathrm{mM}$ slightly decreased the normalized $I_{\mathrm{NaCl}}^{\mathrm{GABA}}$ current from $52 \pm 1 \%(n=4)$ to $48 \pm 1 \%(n=4)$ of values prior to MTSET labeling. The estimated $K_{\mathrm{i}}$ for MTSET inhibition of $I_{\mathrm{NaCl}}^{\mathrm{GABA}}$ was $1.6 \pm 0.2 \mathrm{mM}$. Inclusion of valproate in the labeling buffer significantly enhanced the labeling efficacy of MTSET (see Fig. 2). The half-maximal concentration for the valproate-induced enhancement of MTSET labeling was estimated to be $16 \pm 3 \mathrm{mM}(n=3)$ (Fig. 4b).

Increasing the MTSET incubation time in $\mathrm{NaCl}$ buffer to 20 min decreased the GAT1-mediated, GABA-evoked current to $34 \pm 1 \%$ at $1 \mathrm{mMMTSET}(n=3)$ and $12 \pm 1 \%$ at $2.5 \mathrm{mM}$ MTSET $(n=3)$ (Fig. 4c). Similarly, MTSET incubation in $\mathrm{LiCl}$ buffer for up to $20 \mathrm{~min}$ failed to lead to $100 \%$ elimination of $I_{\mathrm{NaCl}}^{\mathrm{GABA}}$ (Fig. 4c). However, labeling with $2.5 \mathrm{mM}$ MTSET in the presence of Na-valproate for $\geq 10 \mathrm{~min}$ brought about complete elimination of under all conditions GAT1 C74A was functionally insensitive to MTSET exposure. See text for the second-order rate constants for MTSET labeling of WT GAT1 under different conditions. In all experiments, labeling was carried out at $-50 \mathrm{mV}$. In all experiments, the GABA-evoked ( $500 \mu \mathrm{M}$ in $\mathrm{NaCl}$ buffer at $-50 \mathrm{mV})$ current after MTSET modification was normalized to that obtained in the same cell before exposure to MTSET. Reported values represent the mean $\pm \mathrm{SE}$ from three or more oocytes

GAT1-mediated GABA transport (Fig. 4c). The second-order rate constants (Zhang and Karlin 1997) for MTSET labeling of WT GAT1 were determined to be $0.79 \pm 0.21 \mathrm{M}^{-1} \mathrm{~s}^{-1}$ (1 mM MTSET in $\mathrm{NaCl}), 2.0 \pm 0.2 \mathrm{M}^{-1} \mathrm{~s}^{-1} \quad(2.5 \mathrm{mM}$ MTSET in $\mathrm{NaCl}), 1.2 \pm 0.3 \mathrm{M}^{-1} \mathrm{~s}^{-1}$ (1 mM MTSET in $\mathrm{LiCl}), 3.7 \pm 0.4 \mathrm{M}^{-1} \mathrm{~s}^{-1}$ (1 mM MTSET in Na-valproate) and $6.4 \pm 0.5 \mathrm{M}^{-1} \mathrm{~s}^{-1}$ (2.5 mM MTSET in Na-valproate).

Importantly, $I_{\mathrm{NaCl}}^{\mathrm{GABA}}$ mediated by GAT1 C74A was not inhibited by MTSET under any labeling condition (Fig. 4c). Taken together, these results further support the notion that $\mathrm{C} 74$ is only partially exposed to the extracellular fluid and that ionic interactions with the transporter can enhance the solvent accessibility of this residue (Yu et al. 1998; Meinild et al. 2009).

Thus far, the results demonstrate that sulfhydryl modification of GAT1 at C74 leads to a reduction in the GABAevoked current $\left(I_{\mathrm{NaCl}}^{\mathrm{GABA}}\right)$. In order to better understand the 
mechanism by which MTSET labeling of WT GAT1 leads to a reduction in $I_{\mathrm{NaCl}}^{\mathrm{GABA}}$, we carried out a comprehensive characterization of the current that remains after partial labeling with $1 \mathrm{mM}$ MTSET for $5 \mathrm{~min}$ (see Fig. 1). In principle, the reduction in $I_{\mathrm{NaCl}}^{\mathrm{GABA}}$ may be due to (1) a change in the transporter ion/GABA flux coupling ratio; (2) a significant increase in the apparent affinity constant $\left(K_{0.5}\right)$ values (i.e., reduction in the apparent affinity) for the transporter cosubstrates $\mathrm{Na}^{+}, \mathrm{Cl}^{-}$and GABA; (3) a reduction in transporter turnover rate (i.e., the rate at which ion/GABA molecules are cotranslocated across the plasma membrane per unit time); or (4) a complete loss of GAT1 GABA transport activity when $\mathrm{C} 74$ is chemically modified by MTSET. The experiments of Figs. 5, 6, 7, 8 and 9 examine these four possibilities. In all of the following experiments, WT GAT1 was labeled with $1 \mathrm{mM}$ MTSET for $5 \mathrm{~min}$ (at $21 \pm 2{ }^{\circ} \mathrm{C}, V_{\mathrm{m}}=-50 \mathrm{mV}$ and $\mathrm{pH} 7.4$ ) in order to achieve $\sim 50 \%$ reduction in $I_{\mathrm{NaCl}}^{\mathrm{GABA}}$ (see Figs. 1, 2, 3, 4). This "partial labeling" protocol allowed us to carry out a complete functional characterization of $I_{\mathrm{NaCl}}^{\mathrm{GABA}}$ after MTSET labeling.
Sulfhydryl Modification of GAT1 C74 Does Not Alter GAT1-Mediated Charge/GABA Flux Ratio

Translocation of GABA by GAT1 across the plasma membrane is coupled to cotranslocation of $\mathrm{Na}^{+}$and $\mathrm{Cl}^{-}$ (Radian and Kanner 1983; Keynan and Kanner 1988; Loo et al. 2000), and recent studies suggest that $\mathrm{Na}^{+} / \mathrm{Cl}^{-} /$ GABA cotransport is a tightly coupled process (Gonzales et al. 2007; Matthews et al. 2009). To examine the possibility that MTSET modification of C74 leads to a change in the ion/GABA coupling ratio of GAT1, we performed GABA uptake under voltage-clamp experiments (Fig. 5). In these experiments, $\left[{ }^{3} \mathrm{H}\right]-\mathrm{GABA}$ uptake was measured under voltage clamp in individual GAT1-expressing cells in the absence of MTSET labeling (Fig. 5a, c) or after labeling with $1 \mathrm{mM}$ MTSET for $5 \mathrm{~min}$ (at $21 \pm 2{ }^{\circ} \mathrm{C}$, $V_{\mathrm{m}}=-50 \mathrm{mV}$ and $\mathrm{pH}$ 7.4) (Fig. 5b, c). This experimental protocol yielded two measured parameters for each cell: (1) net GABA-evoked inward charge translocation during the recording period (charge flux) and (2) GABA uptake in the same cell (GABA flux) (Fig. 5c). The ratio of charge flux

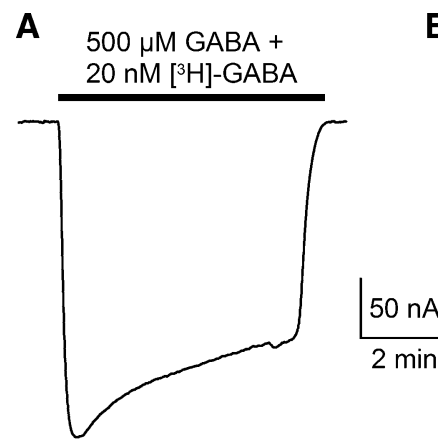

B
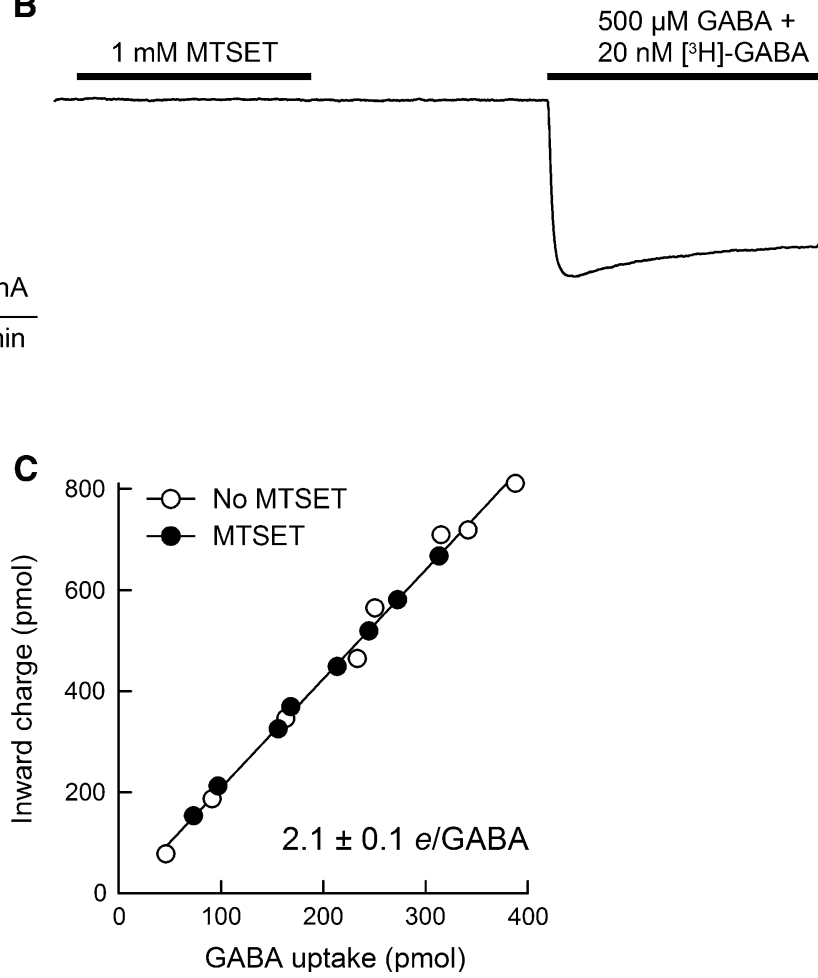

Fig. 5 Sulfhydryl modification of WT GAT1 with MTSET does not alter the ion/GABA transport coupling ratio. GABA-uptake experiments were performed under voltage clamp without MTSET treatment (a) or after labeling with $1 \mathrm{mM}$ MTSET for $5 \mathrm{~min}(\mathbf{b}) . V_{\mathrm{m}}=$ $-50 \mathrm{mV}$. c Cells expressing GAT1 were exposed to $500 \mu \mathrm{M}$ GABA and $20 \mathrm{nM}\left[{ }^{3} \mathrm{H}\right]-\mathrm{GABA}$ for $5-10 \mathrm{~min}$. After washout of GABA and isotope, cells were solubilized in $10 \%$ SDS and intracellular GABA content was determined using a liquid scintillation counter. In the same cell, the net inward charge flux was obtained from the time integral of the GABA-evoked current trace. The ratio of charge flux to GABA flux (i.e., net positive charges per GABA, $e / \mathrm{GABA}$ ) was $2.1 \pm 0.1$ whether or not the cell was exposed to MTSET $(n=8$ and 8 ). The smooth line in (c) is a linear regression through all data points 

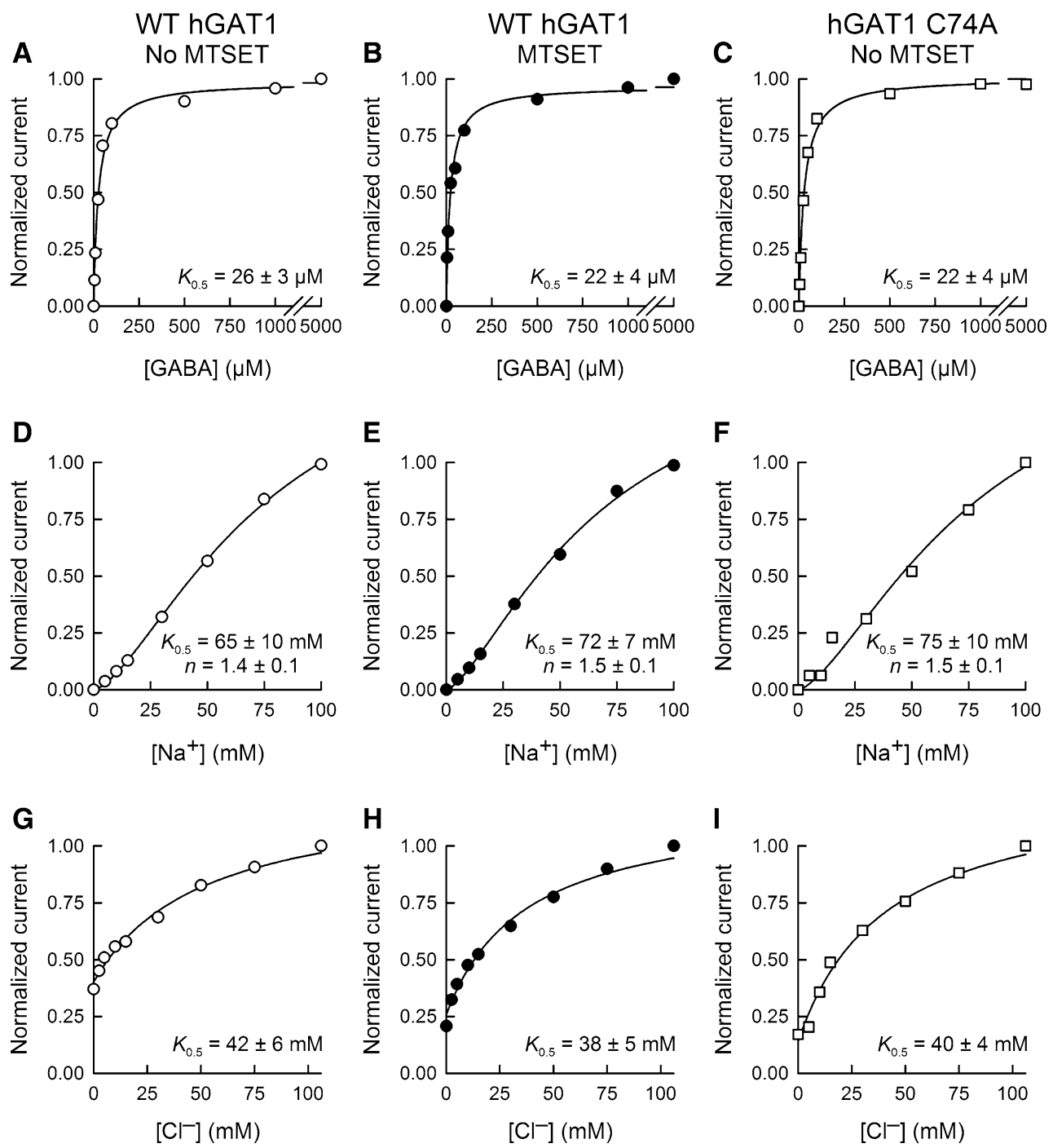

Fig. 6 Steady-state kinetic parameters of WT GAT1 before and after sulfhydryl modification with MTSET. Representative GABA (a-c), $\mathrm{Na}^{+}(\mathbf{d}-\mathbf{f})$ and $\mathrm{Cl}^{-}(\mathbf{g}-\mathbf{i})$ steady-state kinetic curves are shown for WT GAT1 before (left panels) and after (middle panels) treatment with MTSET (1 mM for $5 \mathrm{~min}$ at $-50 \mathrm{mV}$ ) as well as for GAT1 C74A without MTSET treatment (right panels). The half-maximal concentration values $\left(K_{0.5}\right)$ for $\mathrm{GABA}, \mathrm{Na}^{+}$and $\mathrm{Cl}^{-}$were similar for WT GAT1 and GAT1 C74A. The Hill coefficient values for $\mathrm{Na}^{+}$and $\mathrm{Cl}^{-}$ activation of the inward currents were also similar for WT GAT1 and

to GABA flux was $2.1 \pm 0.1$ whether or not the cell was exposed to MTSET (Fig. 5c).

\section{Sulfhydryl Modification of GAT1 C74 Does Not Alter Transporter Steady-State or Presteady-State Kinetic Parameters}

To determine if MTSET modification of GAT1 C74 alters the transporter steady-state kinetic properties, we performed steady-state kinetic experiments for GABA, $\mathrm{Na}^{+}$ and $\mathrm{Cl}^{-}$in WT GAT1 before and after labeling with
GAT1 C74A. Moreover, MTSET exposure had no effect on WT GAT1 steady-state kinetic parameters. $V_{\mathrm{m}}=-50 \mathrm{mV}$. For GABA kinetic experiments (a-c), $\left[\mathrm{Na}^{+}\right]_{0}$ was $100 \mathrm{mM}$ and $\left[\mathrm{Cl}^{-}\right]$was $106 \mathrm{mM}$. For sodium kinetic experiments $(\mathbf{d}-\mathbf{f}),\left[\mathrm{Cl}^{-}\right]$was $106 \mathrm{mM}$ and $[\mathrm{GABA}]_{0}$ was $5 \mathrm{mM}$. For chloride kinetic experiments $(\mathbf{g}-\mathbf{i})$, $\left[\mathrm{Na}^{+}\right]_{0}$ was $100 \mathrm{mM}$ and $[\mathrm{GABA}]_{0}$ was $5 \mathrm{mM}$. The smooth lines represent fits of the experimental data with Eq. 1 (see "Experimental Procedures" Section). Reported values represent the mean \pm SE from three or more oocytes

MTSET (1 $\mathrm{mM}$ for $5 \mathrm{~min}$ in $\mathrm{NaCl}$ buffer) (Fig. 6). The results of these experiments show that the apparent affinity constants for GABA ( $26 \pm 3$ vs. $22 \pm 4 \mu$ M, Fig. $6 a$, b), $\mathrm{Na}^{+}\left(66 \pm 10\right.$ vs. $72 \pm 7 \mathrm{mM}$, Fig. $6 \mathrm{~d}$, e) and $\mathrm{Cl}^{-}$ (42 \pm 6 vs. $38 \pm 5 \mathrm{mM}$, Fig. $6 \mathrm{~g}$, h) were not significantly different before and after partial labeling with $1 \mathrm{mM}$ MTSET for $5 \mathrm{~min}$. Moreover, the Hill coefficient for $\mathrm{Na}^{+}$ activation of the currents was the same before and after sulfhydryl modification of C74 (Fig. 6d, e). The apparent affinity constants of the mutant GAT1 C74A for GABA (22 $\pm 4 \mu \mathrm{M}$, Fig. 6c), $\mathrm{Na}^{+}(75 \pm 10 \mathrm{mM}$, Fig. 6f) and 
A
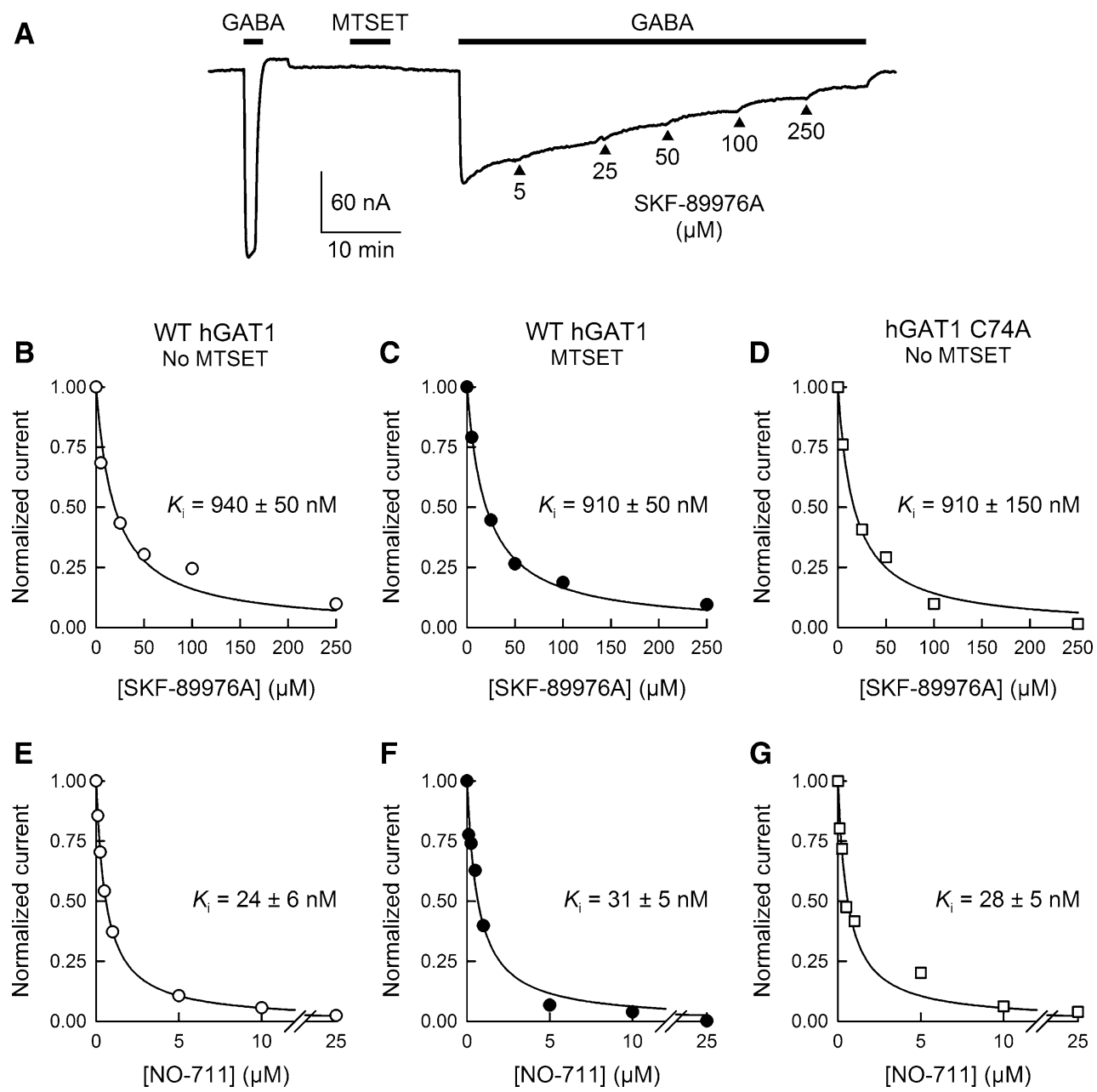

Fig. 7 Sulfhydryl modification with MTSET has no effect on WT GAT1 sensitivity to transport inhibitors. a A representative WT GAT1 current trace is shown for inhibition of the GABA-evoked $(500 \mu \mathrm{M}$ at $-50 \mathrm{mV}$ ) current with SKF-89976A (a specific inhibitor of GAT1) following sulfhydryl modification with MTSET (1 mM for $5 \mathrm{~min}$ at $-50 \mathrm{mV}$ ). Similar to that shown in this panel, inhibition kinetics experiments were performed with SKF-89976A or NO-711 for WT GAT1 without $(\mathbf{b}, \mathbf{e})$ or with $(\mathbf{c}, \mathbf{f})$ prior exposure to MTSET $(1 \mathrm{mM}$ for $5 \mathrm{~min}$ at $-50 \mathrm{mV}$ ) as well as for GAT1 C74A without

$\mathrm{Cl}^{-}$(40 $\pm 4 \mathrm{mM}$, Fig. 6i) were not significantly different from those of WT GAT1.

To further characterize the behavior of WT GAT1 after partial labeling with $1 \mathrm{mM}$ MTSET for $5 \mathrm{~min}$, we investigated the sensitivity of WT GAT1 to known transporter inhibitors before and after sulfhydryl modification (Fig. 7). The apparent half-inhibition constant values for SKF89976A (940 \pm 50 vs. $910 \pm 50 \mathrm{nM}$, Fig. 7b, c) and NO-711 (24 \pm 6 vs. $31 \pm 5$ nM, Fig. 7e, f) were not significantly different before and after sulfhydryl labeling with MTSET. Moreover, the apparent half-inhibition constant values of GAT1 C74A for SKF-89976A $(910 \pm 150 \mathrm{nM}$, Fig. 7d) and NO-711 (28 $\pm 5 \mathrm{nM}$, Fig. $7 \mathrm{~g})$ were similar to those of WT GAT1.
MTSET treatment $(\mathbf{d}, \mathbf{g})$. Sulfhydryl modification of WT GAT1 had no effect on the $K_{\mathrm{i}}$ values for SKF-89976A or NO-711. Moreover, the $K_{\mathrm{i}}$ values for SKF-89976A (d) and NO-711 (g) inhibition of GAT1 C74A GABA-evoked currents were not different from those of WT GAT1. The smooth lines in $(\mathbf{b}-\mathbf{g})$ represent fits of the experimental data with an equation for competitive inhibition at a single binding site (Eq. 4, see "Experimental Procedures" section). Reported $K_{\mathrm{i}}$ values represent the mean \pm SE from three or more oocytes

To examine the effect of MTSET labeling on WT GAT1 voltage-evoked presteady-state currents, 400-ms voltage pulses were applied, from a holding voltage of $-50 \mathrm{mV}$ to test voltages ranging from +80 to $-130 \mathrm{mV}$ in $15-\mathrm{mV}$ steps, before (Fig. 8a) and after (Fig. 8b) labeling with $1 \mathrm{mM}$ MTSET for $5 \mathrm{~min}$. At each voltage, the evoked current transient was analyzed to obtain the GAT1-mediated charge moved (see "Experimental Procedures" Section), and the resulting presteady-state charge was plotted as a function of the test voltage to obtain the $Q-V$ relationships (Fig. 8d, e). After labeling WT GAT1 with $1 \mathrm{mM}$ MTSET for $5 \mathrm{~min}, Q_{\mathrm{NaCl}}$ was reduced to $60 \pm 8 \%$ $(n=4)$ of that prior to MTSET treatment (compare Fig. 8d, e), suggesting a similar degree of loss of function 

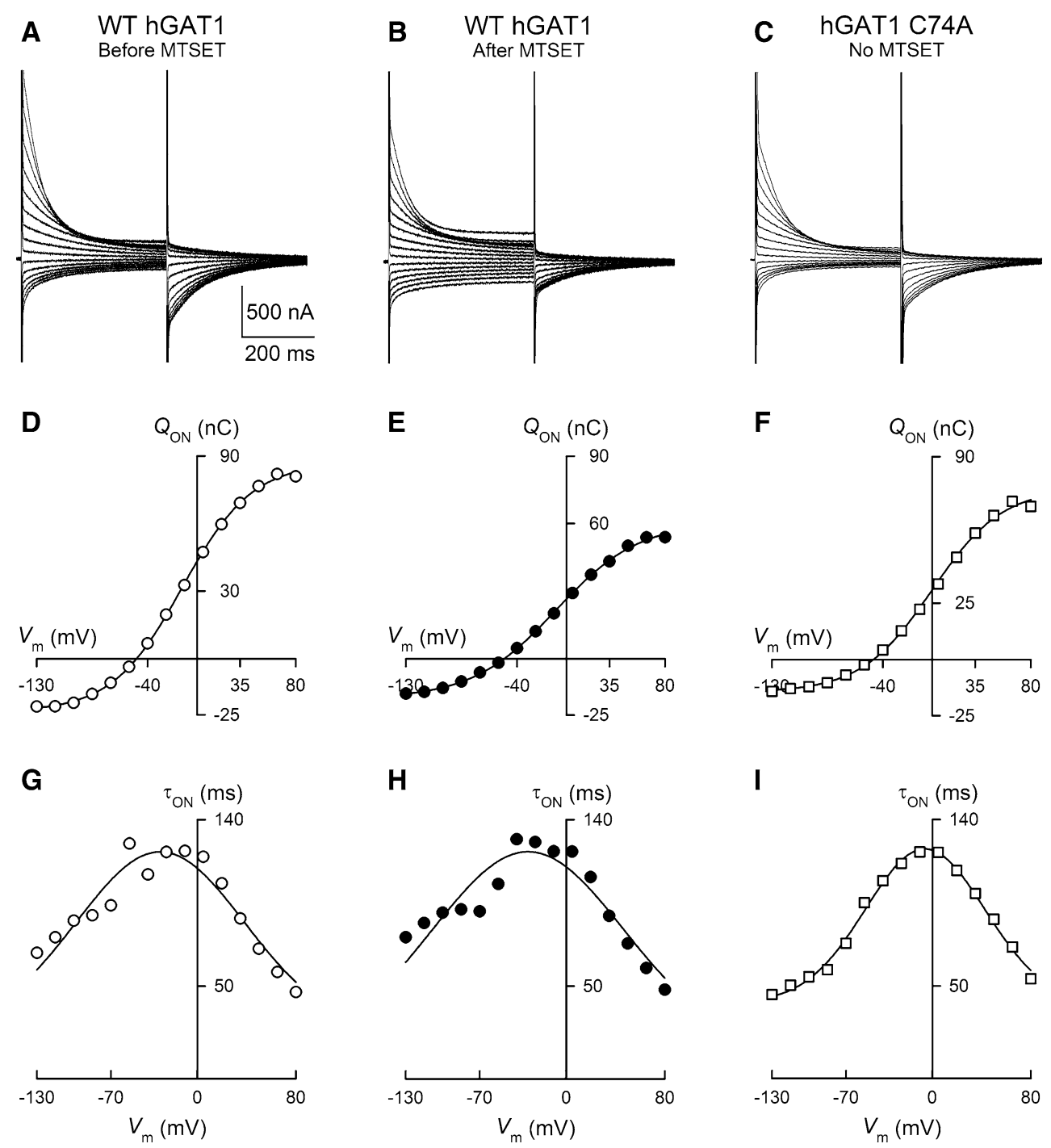

Fig. 8 Presteady-state charge movements of WT GAT1 before and after sulfhydryl modification with MTSET. a-c Representative current relaxations are shown in response to $400-\mathrm{ms}$ voltage pulses from +80 to $-130 \mathrm{mV}$ for WT GAT1 before (a) and after (b) treatment with MTSET (1 $\mathrm{mM}$ for $5 \mathrm{~min}$ ) as well as for GAT1 C74A without MTSET treatment (c). Holding potential was $-50 \mathrm{mV}$. d-f For each evoked current trace, time integration of the $\mathrm{ON}$ presteady-state currents yielded the total charge moved $\left(Q_{\mathrm{ON}}\right)$ and, when plotted as a function of the test voltage, the $Q-V$ relationship for WT GAT1 before (d) and after (e) labeling with MTSET as well as for GAT1 C74A (f). The smooth lines in $(\mathbf{d}-\mathbf{f})$ represent the fit of the data with a

as that seen with steady-state GABA-evoked current $\left(I_{\mathrm{NaCl}}^{\mathrm{GABA}}\right)$ (see Figs. 1, 2, 3). Neither the midpoint of the $Q-V$ relationship ( $V_{0.5}, 25 \pm 5$ vs. $22 \pm 6 \mathrm{mV}$ ) nor the apparent valence of the moveable charge $(z \delta, 0.9 \pm 0.1$ vs. $0.9 \pm 0.1$ ) was different after MTSET treatment (Fig. 8d, e). Furthermore, the ON and OFF relaxation time constants were not altered after MTSET treatment (Fig. 8g, h). Finally, the presteady-state kinetic properties of GAT1 C74A were similar to those of WT GAT1 (Fig. 8c, f, i).
Boltzmann function (Eq. 3, see "Experimental Procedures" section). g-i Presteady-state currents monoexponentially decay to the zero level. The time constant plotted as a function of the test voltage yielded the $\tau-V$ relationship. The smooth lines in $(\mathbf{g}-\mathbf{i})$ represent the fit of the data with a gaussian function (Sacher et al. 2002). While MTSET treatment led to a reduction in the total charge moved (compare d and e), it had no effect on the midpoint of the $Q-V$ relationship $\left(V_{0.5}\right)$ and no effect on the relaxation time constants (compare $\mathbf{g}$ and $\mathbf{h}$ ). The presteady-state parameters of GAT1 C74A were not different from those of WT GAT1. See text for additional details

\section{Sulfhydryl Modification of GAT1 C74 Does Not Alter Transporter Turnover Rate}

Turnover rate is the rate at which ion/GABA molecules are cotranslocated across the plasma membrane per unit time. In a comprehensive characterization, the GAT1 turnover rate was determined to be 15 GABA molecules per second at $21{ }^{\circ} \mathrm{C},-50 \mathrm{mV}$ and physiological ion concentrations (Gonzales et al. 2007). When extrapolated to the 


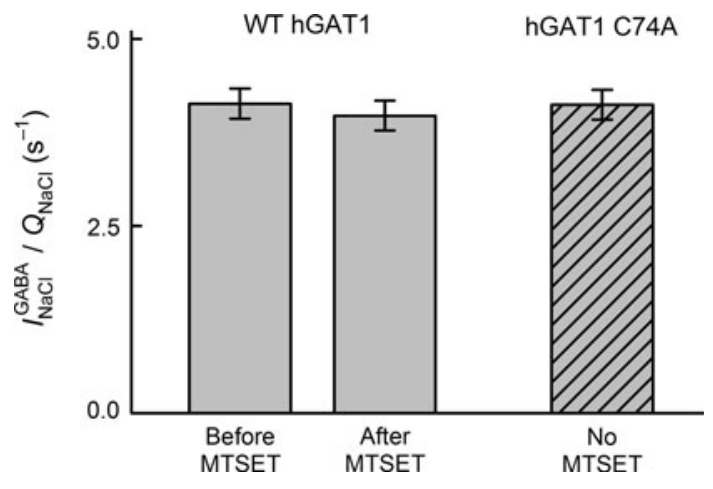

Fig. 9 Sulfhydryl modification with MTSET has no effect on WT GAT1 turnover rate. The ratio of $I_{\mathrm{NaCl}}^{\mathrm{GABA}}$ to $Q_{\mathrm{NaCl}}$ is used as an index of the transporter turnover rate (Gonzales et al. 2007). $I_{\mathrm{NaCl}}^{\mathrm{GABA}}$ represents the maximum GABA-evoked current and was measured at $5 \mathrm{mM}$ GABA and $-50 \mathrm{mV}$ (in $\mathrm{NaCl}$ buffer). $Q_{\mathrm{NaCl}}$ represents the total charge moved in response to ON voltage pulses and was measured in $\mathrm{NaCl}$ buffer according to the procedures described for the experiments of Fig. 8. Sulfhydryl modification with MTSET had no effect on the ratio of $I_{\mathrm{NaCl}}^{\mathrm{GABA}}$ to $Q_{\mathrm{NaCl}}\left(4.1 \pm 0.2\right.$ vs. $4.0 \pm 0.2 \mathrm{~s}^{-1}, n=4$ and 4). The ratio was also similar in GAT1 C74A (4.1 $\left.\pm 0.2 \mathrm{~s}^{-1}, n=7\right)$

physiological temperature of $37^{\circ} \mathrm{C}$, the turnover rate was estimated to be $79 \mathrm{~s}^{-1}$ (Gonzales et al. 2007). An important prerequisite to characterizing the turnover rate is the ratio of the maximum GABA-evoked current $\left(I_{\mathrm{NaCl}}^{\mathrm{GABA}}\right)$ to the maximum presteady-state charge movements $\left(Q_{\mathrm{NaCl}}\right)$. Both $I_{\mathrm{NaCl}}^{\mathrm{GABA}}$ and $Q_{\mathrm{NaCl}}$ are directly proportional to the total number of functional transporters in the cell plasma membrane (Gonzales et al. 2007). The ratio of $I_{\mathrm{NaCl}}^{\mathrm{GABA}}$ to $Q_{\mathrm{NaCl}}$ is directly proportional to the turnover rate and, therefore, can be used as an index of the transporter turnover rate (for details, see Gonzales et al. 2007). At any given membrane potential, the maximum GABA-evoked current $\left(I_{\mathrm{NaCl}}^{\mathrm{GABA}}\right)$ is measured at steady state after application of GABA at a saturating concentration $(\geq 5 \mathrm{mM})$. The maximum presteady-state charge movement $\left(Q_{\mathrm{NaCl}}\right)$ is determined in the absence of GABA from analyzing presteady-state current transients evoked in response to step changes in the membrane potential (Sacher et al. 2002; Whitlow et al. 2003; Karakossian et al. 2005; Gonzales et al. 2007). The results of typical presteady-state charge movement experiments are shown in Fig. 8, and the ratio of $I_{\mathrm{NaCl}}^{\mathrm{GABA}}$ to $Q_{\mathrm{NaCl}}$ is shown in Fig. 9.

The ratio of $I_{\mathrm{NaCl}}^{\mathrm{GABA}}$ to $Q_{\mathrm{NaCl}}$ (i.e., index of turnover rate) for WT GAT1 was the same before and after sulfhydryl modification with $1 \mathrm{mM}$ MTSET for $5 \mathrm{~min}(4.1 \pm 0.2 \mathrm{vs}$. $4.0 \pm 0.2 \mathrm{~s}^{-1}, n=4$ and 4). Moreover, this ratio was similar for GAT1 C74A $\left(4.1 \pm 0.2 \mathrm{~s}^{-1}, n=7\right)$.

\section{Discussion}

In anticipation of utilizing extracellularly oriented, solventexposed cysteine residues of GAT1 for labeling and quantifying the transporter in the plasma membrane, the primary objective of this study was to characterize the functional consequences of sulfhydryl modification of GAT1 with the membrane-impermeant sulfhydryl reagent MTSET. Our results show that exposure of the extracellular surface of WT GAT1 to MTSET resulted in a significant and proportional, yet reversible, decrease in both the steady-state GABA-evoked current as well as the presteady-state charge movements. Labeling proved to be insensitive to changes in membrane potential, temperature and $\mathrm{pH}$. Labeling was relatively insensitive to changes in $\mathrm{Na}^{+}$and/or $\mathrm{Cl}^{-}$concentration when $\mathrm{Na}^{+}$was replaced with cations such as choline or tetraethylammonium or when $\mathrm{Cl}^{-}$was replaced with anions such as gluconate or MES. However, substitution of $\mathrm{Cl}^{-}$with valproate significantly increased the rate of labeling with MTSET, driving it to completion and leading to a complete loss of transporter function.

GAT1 contains 14 cysteine residues, of which only three (C74, C164, C173) are predicted to be exposed to the extracellular fluid. $\mathrm{C} 74$ is in the first transmembrane domain near the membrane/extracellular fluid interface. C164 and C173 are located in the extracellular loop connecting transmembrane domains 3 and 4 , and there is evidence that these as well as homologous residues of the related serotonin and dopamine transporters form a disulfide bridge under most conditions (Chen et al. 1997, 2007). Site-directed mutagenesis revealed that the site of covalent sulfhydryl modification of GAT1 is most likely the cysteine at position 74. Our data cannot rule out the possibility that the functional consequence of labeling is due to modification of a cysteine residue other than $\mathrm{C} 74$, whose accessibility is altered in the mutant C74A. However, considering the totality of our data set (insensitivity of C74A to MTSET and virtually identical steady-state state and presteady-state kinetic properties of WT and GAT1 C74A), it is plausible to conclude that C74 is very likely the only functionally sensitive cysteine residue that is labeled by MTSET. Extensive functional characterization suggested that GAT1 C74 is only partially accessible from the extracellular fluid. However, once covalently modified with MTSET, GAT1 is incapable of undergoing the conformational changes necessary for presteady-state transients or $\mathrm{Na}^{+} / \mathrm{Cl}^{-} / \mathrm{GABA}$ cotranslocation across the plasma membrane.

Our first goal was to optimize the experimental conditions under which all GAT1 copies in the plasma membrane could be rapidly labeled with MTSET, while maintaining cellular and plasma membrane integrity such that accurate biophysical measurements could be carried out. Initial time and concentration dependence of MTSET labeling of GAT1 demonstrated that, under most labeling conditions, very long incubation times at high MTSET 
concentrations are required to approach complete labeling of all transporter copies in the plasma membrane. This observation is not consistent with the very high intrinsic reactivity of methanethiosulfonate reagents toward free thiol groups (Karlin and Akabas 1998) and suggests that C74 is only partially exposed to the extracellular fluid, such that accessibility of this site to MTSET is restricted (Yu et al. 1998). Indeed, sequence alignments of GAT1 with the related bacterial leucine transporter $\left(\operatorname{LeuT}_{\mathrm{Aa}}\right)$ and other members of the SLC6A family of transporters, as well as homology models of GAT1 built using the high-resolution structure of LeuT $\mathrm{T}_{\mathrm{Aa}}$ as a template, strongly suggest that C74 is in the first transmembrane domain near the membrane-extracellular fluid interface and is partially buried in the membrane (Yamashita et al. 2005; Beuming et al. 2006; Livesay et al. 2007). As a practical matter, the relatively short half-life of MTSET in physiological buffers ( $\sim 10 \mathrm{~min}$ ) also necessitates the use of experimental conditions that can achieve faster labeling of GAT1.

As GAT1-mediated GABA transport is $\mathrm{Na}^{+}$- and $\mathrm{Cl}^{-}$coupled, we investigated the degree of MTSET labeling when $\mathrm{Na}^{+}$or $\mathrm{Cl}^{-}$was isosmotically replaced with various cations/anions in the labeling buffer. It is well established that $\mathrm{Na}^{+}$and/or $\mathrm{Cl}^{-}$binding events to GAT1 cause transporter conformational changes (Mager et al. 1993, 1996; Golovanevsky and Kanner 1999; Lu and Hilgemann 1999b; Li et al. 2000; Bicho and Grewer 2005; Karakossian et al. 2005; Meinild et al. 2009). We reasoned that conformational changes induced by $\mathrm{Na}^{+}$and/or $\mathrm{Cl}^{-}$binding may alter the accessibility of C74 to the extracellular space and that, therefore, it was plausible to examine the degree of labeling in buffers that lacked either one or both of these cosubstrates. For most ion replacement conditions tested, only a modest enhancement was observed in the ability of MTSET to label GAT1, as judged by the reduction in the GABA-evoked current (see Fig. 2). Two notable exceptions were replacement of $\mathrm{Na}^{+}$with $\mathrm{Li}^{+}$and replacement of $\mathrm{Cl}^{-}$with valproate.

Consistent with previous reports on GAT1 and the serotonin transporter (SERT), we observed a substantial reduction in transport activity following MTSET labeling when $\mathrm{Li}^{+}$replaced $\mathrm{Na}^{+}$in the labeling buffer (Figs. 2, 4) (Ni et al. 2001; Meinild et al. 2009). In SERT, the increased accessibility of C109 (homologous with GAT1 C74) is due to $\mathrm{Li}^{+}$binding rather than the absence of $\mathrm{Na}^{+}$ (Ni et al. 2001), and this is consistent with our findings in GAT1 (Fig. 2). In GAT1, $\mathrm{Li}^{+}$by itself is not capable of driving $\mathrm{Li}^{+} / \mathrm{Cl}^{-} / \mathrm{GABA}$ cotransport as the $\mathrm{Li}^{+}$-bound transporter conformation is distinct from the $\mathrm{Na}^{+}$-bound conformation (Meinild et al. 2009). However, in the presence of low concentrations of $\mathrm{Na}^{+}, \mathrm{Li}^{+}$can substitute for $\mathrm{Na}^{+}$at one of the cation-binding sites, allowing for $\mathrm{Li}^{+} /$ $\mathrm{Na}^{+} / \mathrm{Cl}^{-} / \mathrm{GABA}$ cotransport (MacAulay et al. 2002;
Meinild and Forster 2012). Thus, in the presence of $\mathrm{Li}^{+}$ $\left(\mathrm{Na}^{+}\right.$absent) GAT1 assumes a distinct conformation with increased accessibility of $\mathrm{C} 74$ to the extracellular fluid.

Remarkably, the most significant environmental condition which favored GAT1 labeling by MTSET was when $\mathrm{Cl}^{-}$was replaced with valproate (Figs. 2, 4). Valproate increases the turnover rate of the GATs via an allosteric mechanism that involves increasing the rate of $\mathrm{Na}^{+}$binding to the transporter, the transition that is thought to be the rate-limiting step in the transport cycle (Whitlow et al. 2003; Soragna et al. 2005). Our data show that in the presence of valproate complete MTSET labeling of GAT1 can be accomplished within $10 \mathrm{~min}$ (Fig. 4c) and suggest that any future attempts to utilize C74 to label GAT1 in the plasma membrane should use valproate as the major anion in the labeling buffer.

Interestingly, the presence of GABA protected GAT1 from MTSET labeling (Fig. 2) (Zhou et al. 2004). This suggests that during the normal translocation cycle (i.e., $\mathrm{Na}^{+} / \mathrm{Cl}^{-} / \mathrm{GABA}$ cotranslocation) there is a reduction in the probability (i.e., time) that $\mathrm{C} 74$ is exposed to the extracellular fluid and, hence, accessible to covalent modification by MTSET.

We found it surprising that the accessibility of GAT1 C74 to the extracellular fluid and, hence, MTSET was not altered by changes in experimental conditions such as membrane potential, temperature or $\mathrm{pH}$. GAT1 function is highly voltage-dependent, and indeed, voltage-clamp fluorometric measurements have provided strong evidence for conformational changes evoked by voltage jumps ( $\mathrm{Li}$ et al. 2000; Meinild et al. 2009). Moreover, the rates of both GAT1 steady-state and presteady-state kinetic properties are very temperature-dependent (Binda et al. 2002; Gonzales et al. 2007). Finally, changes in the extracellular $\mathrm{pH}$ have been reported to alter GAT1 function (Grossman and Nelson 2002, 2003). Nonetheless, none of these conditions appeared to play a significant role in the ability of MTSET to label GAT1, suggesting that the global conformational changes caused by these factors do not lead to a change in the accessibility of $\mathrm{C} 74$ to the extracellular fluid. When labeling was performed at $\mathrm{pH}$ 5.0, there appeared to be a decrease in the efficacy of MTSET; however, this was very likely due to the significantly decreased fraction of GAT1 C74 in the deprotonated thiol form - the form that can nucleophilically attack and, thus, react with MTSET. With a $\mathrm{p} K_{\mathrm{a}}$ of $\sim 8.37$, only $0.04 \%$ of C74 thiol groups are predicted to be in the deprotonated form at $\mathrm{pH} 5.0$ (vs. 9.7 and $19.0 \%$ at $\mathrm{pH} 7.4$ and 9.0, respectively). Indeed, there appeared to be a correlation between the fraction of $\mathrm{C} 74$ in the deprotonated form and loss of transporter function following MTSET treatment (13, 47 and $56 \%$ at $\mathrm{pH} 5.0,7.4$ and 9.0, respectively) (see Fig. 3 for raw data). 
Having found improved experimental conditions for sulfhydryl modification of GAT1 C74 with MTSET (i.e., labeling in the presence of valproate), we wished to understand the mechanism by which MTSET labeling of GAT1 C74 leads to a reduction in the GABA-evoked current $\left(I_{\mathrm{NaCl}}^{\mathrm{GABA}}\right)$. In principle, the reduction in $I_{\mathrm{NaCl}}^{\mathrm{GABA}}$ may be due to (1) a change in the transporter ion/GABA flux coupling ratio (i.e., change in ion/substrate transport stoichiometry); (2) a significant increase in the apparent affinity constant $\left(K_{0.5}\right)$ values (i.e., reduction in the apparent affinity) for the transporter cosubstrates $\mathrm{Na}^{+}, \mathrm{Cl}^{-}$and GABA; (3) a reduction in transporter turnover rate (i.e., the rate at which ion/GABA molecules are cotranslocated across the plasma membrane per unit time); or (4) a complete loss of GAT1 GABA transport activity when C74 is chemically modified by MTSET. To study each of these possibilities, we characterized the current that remained after partial labeling of GAT1 with MTSET. Partial labeling was achieved by incubating GAT1 with $1 \mathrm{mM}$ MTSET for $5 \mathrm{~min}$ (at $21{ }^{\circ} \mathrm{C}, V_{\mathrm{m}}=-50 \mathrm{mV}, \mathrm{pH} 7.4$ ) in order to achieve $\sim 50 \%$ reduction in $I_{\mathrm{NaCl}}^{\mathrm{GABA}}$ (see Figs. 1, 2, 3, 4).

The results of uptake under voltage-clamp experiments suggest that the current that remains after MTSET sulfhydryl modification of GAT1 has the same ion/GABA flux coupling ratio as that mediated by untreated GAT1: two net positive charges for every GABA molecule translocated across the plasma membrane (Fig. 5). GAT1 exhibits tight coupling of charge flux and GABA flux under a variety of experimental conditions, which suggests a fixed ion/substrate transport stoichiometry (Gonzales et al. 2007; Matthews et al. 2009). Therefore, if labeling with MTSET alters the transport stoichiometry, the ratio of charge flux to GABA flux should shift from the known value of 2. Our results do not support this possibility. Thus, after MTSET treatment, the GABA-evoked current is mediated by transporters that operate with a normal $\mathrm{Na}^{+} / \mathrm{Cl}^{-} / \mathrm{GABA}$ coupling stoichiometry.

After MTSET treatment, the remaining GABA-evoked current had the same steady-state and presteady-state kinetic parameters, as well as pharmacological properties, as those of untreated GAT1 (Figs. 6, 7, 8). Thus, a reduction in the apparent affinity of the cosubstrates cannot account for the observed reduction in $I_{\mathrm{NaCl}}^{\mathrm{GAB}}$ after MTSET treatment.

After MTSET treatment, the GATs that contribute to the observed macroscopic signal have the same turnover rate as that of untreated GAT1 (Fig. 9). While the exact turnover rate of the GATs and, in fact, most electrogenic $\mathrm{Na}^{+}$-coupled transporters has been elusive due to technical limitations (Gonzales et al. 2007), we have at our disposal a simple measurement that provides an index of the transporter turnover rate. The ratio of the maximum steady-state GABAevoked current $\left(I_{\max }\right)$ to the maximum presteady-state charge moved in response to voltage pulses $\left(Q_{\mathrm{NaCl}}\right.$ or $\left.Q_{\max }\right)$ correlates with the transporter turnover rate (Loo et al. 1993; Mager et al. 1993; Eskandari et al. 1997; Sacher et al. 2002; Whitlow et al. 2003; Karakossian et al. 2005; Gonzales et al. 2007). These two parameters are independently measured in individual GAT1-expressing cells, and each is directly related to the total number of functional transporters in the plasma membrane (Zampighi et al. 1995; Eskandari et al. 1997, 1998; Gonzales et al. 2007). Our results demonstrated that, while both $I_{\max }$ and $Q_{\max }$ are reduced after labeling (see Figs. 1 and 8), the ratio of $I_{\max }$ to $Q_{\max }$ was not altered following MTSET labeling (Fig. 9), suggesting that both parameters were reduced proportionally and that the transporter population that gives rise to these measurements operates with the same turnover rate.

All in all, our data suggest that the observed current following partial labeling with MTSET is mediated by an unlabeled transporter population that operates normally. Transmembrane domain 1 is thought to play a prominent role in GAT1 function by lining the permeation pathway and containing determinants for substrate specificity (Mager et al. 1996; Zhou et al. 2004; Yamashita et al. 2005). It is highly unlikely that the bulky, positively charged MTSET, covalently bonded to C74 at the extracellular end of transmembrane domain 1 , does not alter the transport stoichiometry or any of the relevant steady-state, presteady-state or inhibition kinetic parameters of GAT1. It is more likely that the observed GABA-evoked current following MTSET exposure is mediated by transporters that were simply never labeled. We conclude that MTSET labels GAT1 at C74 and that such covalent sulfhydryl modification renders that transporter completely nonfunctional and electrically silent.

At this time, it is difficult to reconcile our data with those reported previously using the voltage-clamp fluorometry method (Li et al. 2000; Meinild et al. 2009). The totality of our data suggests that labeling C74 with MTSET renders the transporter nonfunctional as all known electrical signals of GAT1 are abolished after labeling. These signals include the GABA-evoked steady-state current as well as voltageevoked presteady-state charge movements. Thus, at first glance, it appears that a fluorophore-conjugated C74 is not a suitable experimental model by which to examine transporter conformational changes that are relevant to those operating during the normal transport cycle. However, previous measurements obtained with the voltage-clamp fluorometry method suggest that GAT1 conjugated (reportedly at C74) with TMR6M exhibits voltage-induced changes in fluorescence intensity and that the time course of these transitions corresponds well to the relaxation time constants of the presteady-state charge movements. Our data show that TMR6M is capable of labeling both WT GAT1 and the mutant GAT1 C74A (see Fig. 1d), suggesting that, in 
addition to $\mathrm{C} 74$, this agent labels other cysteine residues, possibly those buried in the membrane or even exposed to the cytoplasmic space. Clearly, additional studies are needed to better understand the electrophysiological and fluorescence signals following GAT1 labeling with TMR6M. A challenge with selecting suitable fluorescent probes is that their lipid solubility coefficients are generally not known or cannot be estimated (for proprietary molecules). We propose that the simple assay shown here on GAT1 C74A may be performed in order to assess the ability of the fluorophore to cross the plasma membrane and, hence, gain access to internally exposed cysteine residues.

A sequence alignment for members of the neurotransmitter/ $\mathrm{Na}^{+}$symporter family (NSS) reveals that the cysteine at position 74 of GAT1 is conserved in most of the mammalian members of the family. However, each family member is predicted to have different numbers of extracellularly oriented cysteine residues, making it difficult to utilize a single residue for labeling purposes without engineering cysteine mutants against a cysteine-less background. Moreover, very different observations have been reported regarding the functional consequence of labeling with the membrane-impermeant MTSET. For example, WT dopamine and norepinephrine transporters appear to be insensitive to functional modification by extracellularly applied MTSET (Sucic and Bryan-Lluka 2005). The SERT exhibits significant functional sensitivity to MTSET only when $\mathrm{Li}^{+}$is the major extracellular cation, and this effect is abolished in the C109A mutant, where SERT C109 is homologous to GAT1 C74 (Chen et al. 1997; Ni et al. 2001; Sucic and Bryan-Lluka 2005). In the glycine transporter (GlyT1b), MTSET leads to a reduction in both steady-state and voltage-evoked presteady-state currents, and this effect is eliminated in the corresponding cysteineto-alanine mutant (Roux et al. 2001). The basic observations presented here on sulfhydryl modification of GAT1 with MTSET are similar to those reported for the glycine transporter GlyT1b (Roux et al. 2001).

Acknowledgements We thank Jessica Martinez for technical assistance. This work was supported by a U.S. National Institute of General Medical Sciences grant awarded to S. E. (SC1GM086344).

Open Access This article is distributed under the terms of the Creative Commons Attribution License which permits any use, distribution, and reproduction in any medium, provided the original author(s) and the source are credited.

\section{References}

Anderson CM, Kidd PD, Eskandari S (2010) GATMD: $\gamma$-aminobutyric acid transporter mutagenesis database. Database (Oxford) 2010:baq028
Ben-Yona A, Kanner BI (2009) Transmembrane domain 8 of the $\gamma$-aminobutyric acid transporter GAT-1 lines a cytoplasmic accessibility pathway into its binding pocket. J Biol Chem 284:9727-9732

Bennett ER, Kanner BI (1997) The membrane topology of GAT-1, a $\left(\mathrm{Na}^{+}+\mathrm{Cl}^{-}\right)$-coupled $\gamma$-aminobutyric acid transporter from rat brain. J Biol Chem 272:1203-1210

Beuming T, Shi L, Javitch JA, Weinstein H (2006) A comprehensive structure-based alignment of prokaryotic and eukaryotic neurotransmitter $/ \mathrm{Na}^{+}$symporters (NSS) aids in the use of the LeuT structure to probe NSS structure and function. Mol Pharmacol 70:1630-1642

Bicho A, Grewer C (2005) Rapid substrate-induced charge movements of the GABA transporter GAT1. Biophys J 89:211-231

Binda F, Bossi E, Giovannardi S, Forlani G, Peres A (2002) Temperature effects on the presteady-state and transport-associated currents of GABA cotransporter rGAT1. FEBS Lett 512: 303-307

Blakely RD, Berson HE, Fremeau RT Jr, Caron MG, Peek MM, Prince HK, Bradley CC (1991) Cloning and expression of a functional serotonin transporter from rat brain. Nature 354: $66-70$

Borden LA (1996) GABA transporter heterogeneity: pharmacology and cellular localization. Neurochem Int 29:335-356

Busch W, Saier MH Jr (2002) The transporter classification (TC) system, 2002. Crit Rev Biochem Mol Biol 37:287-337

Chen JG, Liu-Chen S, Rudnick G (1997) External cysteine residues in the serotonin transporter. Biochemistry 36:1479-1486

Chen NH, Reith ME, Quick MW (2004) Synaptic uptake and beyond: the sodium- and chloride-dependent neurotransmitter transporter family SLC6. Pflugers Arch 447:519-531

Chen R, Wei H, Hill ER, Chen L, Jiang L, Han DD, Gu HH (2007) Direct evidence that two cysteines in the dopamine transporter form a disulfide bond. Mol Cell Biochem 298:41-48

Conti F, Minelli A, Melone M (2004) GABA transporters in the mammalian cerebral cortex: localization, development and pathological implications. Brain Res Brain Res Rev 45:196-212

Dalby NO (2003) Inhibition of $\gamma$-aminobutyric acid uptake: anatomy, physiology and effects against epileptic seizures. Eur J Pharmacol 479:127-137

Eskandari S, Loo DD, Dai G, Levy O, Wright EM, Carrasco N (1997) Thyroid $\mathrm{Na}^{+} / \mathrm{I}^{-}$symporter. Mechanism, stoichiometry, and specificity. J Biol Chem 272:27230-27238

Eskandari S, Wright EM, Kreman M, Starace DM, Zampighi GA (1998) Structural analysis of cloned plasma membrane proteins by freeze-fracture electron microscopy. Proc Natl Acad Sci USA 95:11235-11240

Forster IC, Loo DD, Eskandari S (1999) Stoichiometry and $\mathrm{Na}^{+}$ binding cooperativity of rat and flounder renal type II $\mathrm{Na}^{+}-\mathrm{P}_{\mathrm{i}}$ cotransporters. Am J Physiol Renal Physiol 276:F644-F649

Frillingos S, Sahin-Tóth M, Wu J, Kaback HR (1998) Cys-scanning mutagenesis: a novel approach to structure function relationships in polytopic membrane proteins. FASEB J 12:1281-1299

Golovanevsky V, Kanner BI (1999) The reactivity of the $\gamma$-aminobutyric acid transporter GAT-1 toward sulfhydryl reagents is conformationally sensitive. Identification of a major target residue. J Biol Chem 274:23020-23026

Gonzales AL, Lee W, Spencer SR, Oropeza RA, Chapman JV, Ku JY, Eskandari S (2007) Turnover rate of the $\gamma$-aminobutyric acid transporter GAT1. J Membr Biol 220:33-51

Grossman TR, Nelson N (2002) Differential effect of pH on sodium binding by the various GABA transporters expressed in Xenopus oocytes. FEBS Lett 527:125-132

Grossman TR, Nelson N (2003) Effect of sodium lithium and proton concentrations on the electrophysiological properties of the four mouse GABA transporters expressed in Xenopus oocytes. Neurochem Int 43:431-443 
Guan L, Kaback HR (2007) Site-directed alkylation of cysteine to test solvent accessibility of membrane proteins. Nat Protoc 2:2012-2017

Guastella J, Nelson N, Nelson H, Czyzyk L, Keynan S, Miedel MC, Davidson N, Lester HA, Kanner BI (1990) Cloning and expression of a rat brain GABA transporter. Science 249:1303-1306

Guastella J, Brecha N, Weigmann C, Lester HA, Davidson N (1992) Cloning, expression, and localization of a rat brain high-affinity glycine transporter. Proc Natl Acad Sci USA 89:7189-7193

Hazama A, Loo DD, Wright EM (1997) Presteady-state currents of the rabbit $\mathrm{Na}^{+}$/glucose cotransporter (SGLT1). J Membr Biol 155:175-186

Hoffman BJ, Mezey E, Brownstein MJ (1991) Cloning of a serotonin transporter affected by antidepressants. Science 254:579-580

Kanner BI (2003) Transmembrane domain I of the $\gamma$-aminobutyric acid transporter GAT-1 plays a crucial role in the transition between cation leak and transport modes. J Biol Chem 278: 3705-3712

Karakossian MH, Spencer SR, Gomez AQ, Padilla OR, Sacher A, Loo DD, Nelson N, Eskandari S (2005) Novel properties of a mouse $\gamma$-aminobutyric acid transporter (GAT4). J Membr Biol 203:65-82

Karlin A, Akabas MH (1998) Substituted-cysteine accessibility method. Meth Enzymol 293:123-145

Keynan S, Kanner BI (1988) $\gamma$-Aminobutyric acid transport in reconstituted preparations from rat brain: coupled sodium and chloride fluxes. Biochemistry 27:12-17

Kilty JE, Lorang D, Amara SG (1991) Cloning and expression of a cocaine-sensitive rat dopamine transporter. Science 254:578-579

Krause S, Schwarz W (2005) Identification and selective inhibition of the channel mode of the neuronal GABA transporter 1. Mol Pharmacol 68:1728-1735

Li M, Farley RA, Lester HA (2000) An intermediate state of the $\gamma$ aminobutyric acid transporter GAT1 revealed by simultaneous voltage clamp and fluorescence. J Gen Physiol 115:491-508

Liu QR, Nelson H, Mandiyan S, López-Corcuera B, Nelson N (1992) Cloning and expression of a glycine transporter from mouse brain. FEBS Lett 305:110-114

Livesay DR, Kidd PD, Eskandari S, Roshan U (2007) Assessing the ability of sequence-based methods to provide functional insight within membrane integral proteins: a case study analyzing the neurotransmitter $/ \mathrm{Na}^{+}$symporter family. BMC Bioinformatics 8:397

Loo DD, Hazama A, Supplisson S, Turk E, Wright EM (1993) Relaxation kinetics of the $\mathrm{Na}^{+}$/glucose cotransporter. Proc Natl Acad Sci USA 90:5767-5771

Loo DD, Eskandari S, Boorer KJ, Sarkar HK, Wright EM (2000) Role of $\mathrm{Cl}^{-}$in electrogenic $\mathrm{Na}^{+}$-coupled cotransporters GAT1 and SGLT1. J Biol Chem 275:37414-37422

Lu CC, Hilgemann DW (1999a) GAT1 (GABA: $\mathrm{Na}^{+}: \mathrm{Cl}^{-}$) cotransport function. Steady state studies in giant Xenopus oocyte membrane patches. J Gen Physiol 114:429-444

Lu CC, Hilgemann DW (1999b) GAT1 (GABA: $\mathrm{Na}^{+}: \mathrm{Cl}^{-}$) cotransport function. Kinetic studies in giant Xenopus oocyte membrane patches. J Gen Physiol 114:445-457

MacAulay N, Zeuthen T, Gether U (2002) Conformational basis for the $\mathrm{Li}^{+}$-induced leak current in the rat $\gamma$-aminobutyric acid (GABA) transporter-1. J Physiol 544:447-458

Madsen KK, White HS, Schousboe A (2010) Neuronal and nonneuronal GABA transporters as targets for antiepileptic drugs. Pharmacol Ther 125:394-401

Mager S, Naeve J, Quick M, Labarca C, Davidson N, Lester HA (1993) Steady states, charge movements, and rates for a cloned GABA transporter expressed in Xenopus oocytes. Neuron 10:177-188

Mager S, Kleinberger-Doron N, Keshet GI, Davidson N, Kanner BI, Lester HA (1996) Ion binding and permeation at the GABA transporter GAT1. J Neurosci 16:5405-5414
Mari SA, Soragna A, Castagna M, Santacroce M, Perego C, Bossi E, Peres A, Sacchi VF (2006) Role of the conserved glutamine 291 in the rat $\gamma$-aminobutyric acid transporter rGAT-1. Cell Mol Life Sci 63:100-111

Matthews E Jr, Rahnama-Vaghef A, Eskandari S (2009) Inhibitors of the $\gamma$-aminobutyric acid transporter 1 (GAT1) do not reveal a channel mode of conduction. Neurochem Int 55:732-740

Meinild AK, Forster IC (2012) Using lithium to probe sequential cation interactions with GAT1. Am J Physiol Cell Physiol 302: C1661-C1675

Meinild AK, Loo DD, Skovstrup S, Gether U, Macaulay N (2009) Elucidating conformational changes in the $\gamma$-aminobutyric acid transporter-1. J Biol Chem 284:16226-16235

Nelson H, Mandiyan S, Nelson N (1990) Cloning of the human brain GABA transporter. FEBS Lett 269:181-184

Nelson N (1998) The family of $\mathrm{Na}^{+} / \mathrm{Cl}^{-}$neurotransmitter transporters. J Neurochem 71:1785-1803

Ni YG, Chen JG, Androutsellis-Theotokis A, Huang CJ, Moczydlowski E, Rudnick G (2001) A lithium-induced conformational change in serotonin transporter alters cocaine binding, ion conductance, and reactivity of Cys-109. J Biol Chem 276:30942-30947

Pacholczyk T, Blakely RD, Amara SG (1991) Expression cloning of a cocaine- and antidepressant-sensitive human noradrenaline transporter. Nature 350:350-354

Radian R, Kanner BI (1983) Stoichiometry of sodium- and chloridecoupled $\gamma$-aminobutyric acid transport by synaptic plasma membrane vesicles isolated from rat brain. Biochemistry 22: $1236-1241$

Richerson GB, Wu Y (2003) Dynamic equilibrium of neurotransmitter transporters: not just for reuptake anymore. J Neurophysiol 90:1363-1374

Rosenberg A, Kanner BI (2008) The substrates of the GABA transporter GAT-1 induce structural rearrangements around the interface of transmembrane domains 1 and 6. J Biol Chem 283: 14376-14383

Roux MJ, Martinez-Maza R, Le Goff A, Lopez-Corcuera B, Aragon C, Supplisson S (2001) The glial and the neuronal glycine transporters differ in their reactivity to sulfhydryl reagents. J Biol Chem 276:17699-17705

Rudnick G (2006) Serotonin transporters-structure and function. J Membr Biol 213:101-110

Sacher A, Nelson N, Ogi JT, Wright EM, Loo DD, Eskandari S (2002) Presteady-state and steady-state kinetics and turnover rate of the mouse $\gamma$-aminobutyric acid transporter (mGAT3). J Membr Biol 190:57-73

Saier MH Jr, Tran CV, Barabote RD (2006) TCDB: the transporter classification database for membrane transport protein analyses and information. Nucleic Acids Res 34:D181-D186

Schousboe A, Madsen KK, White HS (2011) GABA transport inhibitors and seizure protection: the past and future. Future Med Chem 3:183-187

Shimada S, Kitayama S, Lin CL, Patel A, Nanthakumar E, Gregor P, Kuhar M, Uhl G (1991) Cloning and expression of a cocainesensitive dopamine transporter complementary DNA. Science 254:576-578

Soragna A, Bossi E, Giovannardi S, Pisani R, Peres A (2005) Relations between substrate affinities and charge equilibration rates in the rat GABA cotransporter GAT1. J Physiol 562: $333-345$

Sucic S, Bryan-Lluka LJ (2005) Roles of transmembrane domain 2 and the first intracellular loop in human noradrenaline transporter function: pharmacological and SCAM analysis. J Neurochem 94:1620-1630

Usdin TB, Mezey E, Chen C, Brownstein MJ, Hoffman BJ (1991) Cloning of the cocaine-sensitive bovine dopamine transporter. Proc Natl Acad Sci USA 88:11168-11171 
Whitlow RD, Sacher A, Loo DD, Nelson N, Eskandari S (2003) The anticonvulsant valproate increases the turnover rate of $\gamma$-aminobutyric acid transporters. J Biol Chem 278:17716-17726

Yamashita A, Singh SK, Kawate T, Jin Y, Gouaux E (2005) Crystal structure of a bacterial homologue of $\mathrm{Na}^{+} / \mathrm{Cl}^{-}$-dependent neurotransmitter transporters. Nature 437:215-223

Yu N, Cao Y, Mager S, Lester HA (1998) Topological localization of cysteine 74 in the GABA transporter, GAT1, and its importance in ion binding and permeation. FEBS Lett 426:174-178

Zampighi GA, Kreman M, Boorer KJ, Loo DD, Bezanilla F, Chandy G, Hall JE, Wright EM (1995) A method for determining the unitary functional capacity of cloned channels and transporters expressed in Xenopus laevis oocytes. J Membr Biol 148:65-78

Zhang H, Karlin A (1997) Identification of acetylcholine receptor channel-lining residues in the M1 segment of the $\beta$-subunit. Biochemistry 36:15856-15864

Zhou Y, Kanner BI (2005) Transporter-associated currents in the $\gamma$-aminobutyric acid transporter GAT-1 are conditionally impaired by mutations of a conserved glycine residue. J Biol Chem 280:20316-20324

Zhou Y, Bennett ER, Kanner BI (2004) The aqueous accessibility in the external half of transmembrane domain I of the GABA transporter GAT-1 is modulated by its ligands. J Biol Chem 279:13800-13808

Zhou Y, Zomot E, Kanner BI (2006) Identification of a lithium interaction site in the $\gamma$-aminobutyric acid (GABA) transporter GAT-1. J Biol Chem 281:22092-22099

Zomot E, Kanner BI (2003) The interaction of the $\gamma$-aminobutyric acid transporter GAT-1 with the neurotransmitter is selectively impaired by sulfhydryl modification of a conformationally sensitive cysteine residue engineered into extracellular loop IV. J Biol Chem 278:42950-42958

Zomot E, Zhou Y, Kanner BI (2005) Proximity of transmembrane domains 1 and 3 of the $\gamma$-aminobutyric acid transporter GAT-1 inferred from paired cysteine mutagenesis. J Biol Chem 280:25512-25516 